\title{
A VIDEO SELF-MODELING INTERVENTION TO MODIFY AGGRESSIVE BEHAVIORS IN STUDENTS WITH AUTISM SPECTRUM DISORDER AND INTELLECTUAL DISABILITIES
}

\author{
By \\ Kate Marie Sadler \\ B.S. Southeast Missouri State University, 2001
}

M.Ed. University of Missouri, 2012

A Dissertation Submitted to the Graduate Faculty of the University of Missouri In Partial Fulfillment of the Requirements for the Degree DOCTOR OF PHILOSOPHY

University of Missouri

Columbia, Missouri

May 2018 
C Copyright by Kate M. Sadler 2018

All Rights Reserved 


\section{APPROVAL PAGE}

The undersigned, appointed by the dean of the Graduate School, have examined the dissertation entitled

\section{A VIDEO SELF-MODELING INTERVENTION TO MODIFY AGGRESSIVE BEHAVIORS IN STUDENTS WITH AUTISM SPECTRUM DISORDER AND INTELLECTUAL DISABILITIES}

presented by Kate Marie Sadler,

a candidate for the degree of doctor of philosophy in Special Education and hereby certify that, in their opinion, it is worthy of acceptance.

Professor Delinda van Garderen

Professor Janine Stichter

Professor Rebecca McCathern

Professor Chad Rose

Doctor David Beversdorf 


\section{DEDICATION}

This dissertation is dedicated to my daughter for her title suggestion, "Everybody's Brain Works Different." To my husband for his endless love and patience.

To my mother for her courage. To my father for always finding a solution. To Kate Becker who believes that I can, when I think I can't. To my advisor who rises to any challenge and suggests that, "we'll get there." 


\section{ACKNOWLEDGEMENTS}

Words do not adequately express my appreciation for my advisor, Delinda van Garderen. Her perseverance, kindness, intellect, strength, compassion, and courage are just a few of the reasons that this manuscript is complete. Her natural demeanor evokes a feeling of awe and that anything is possible with hard work and dedication. She has inspired me to believe in myself, by taking time to get to know me and challenging me to be my best self. Dr. VG, your words and advice will remain with me forever and inspire me to be a better scholar and a better person.

I must acknowledge as well the many friends, colleagues, and other professors who assisted, advised, and supported my research and writing efforts over the years. These individuals have consistently helped me keep perspective on what is important in life, picked me up when I was down, and showed me how to deal with reality.

My thanks is extended to Stephanie Rieker, Danielle Pizark, Caitlyn Freshour, and Becky Kostecki. Thank you for your input and feedback. Most importantly, thank you for trusting me with the students that you hold so dear. Your drive to help these students succeed is infectious and I will forever be inspired by you.

Finally, I would like to acknowledge "David" and "Nate," whose patience with me, bravery to try something new, and perseverance will likely guide the way to help individuals like themselves. 
TABLE OF CONTENTS

$\begin{array}{lc} & \text { Page } \\ \text { ACKNOWLEDGEMENT PAGE } & \text { ii } \\ \text { TABLE OF CONTENTS } & \text { iii } \\ \text { LIST OF TABLES } & \text { vi } \\ \text { LIST OF FIGURES } & \text { vii } \\ \text { ABSTRACT } & \text { viii }\end{array}$

CHAPTER 1

INTRODUCTION 1

ASD and Intellectual Disabilities (ID) 2

School Based Treatments for Aggression $\quad 4$

$\begin{array}{ll}\text { Rationale for Current Study } & 7\end{array}$

CHAPTER 2

$\begin{array}{ll}\text { LITERATURE REVIEW } & 10\end{array}$

$\begin{array}{ll}\text { Social Cognitive Theory } & 12\end{array}$

$\begin{array}{ll}\text { Overview of Video Self-Modeling (VSM) } & 15\end{array}$

ASD and School Based Video Self-Modeling (VSM) 17

$\begin{array}{ll}\text { Purpose of the Current Study } & 23\end{array}$

CHAPTER 3 
$\begin{array}{ll}\text { METHODS } & 26\end{array}$

$\begin{array}{ll}\text { Participants } & 27\end{array}$

Participant Preferences and Function of Aggressive Behavior 29

Research Design 32

$\begin{array}{ll}\text { VSM Features } & 35\end{array}$

Data Collection 36

$\begin{array}{ll}\text { Treatment Fidelity } & 38\end{array}$

Inter-Observer Training and Agreement 38

Social Validity 39

CHAPTER 4

$\begin{array}{ll}\text { RESULTS } & 41\end{array}$

Visual Analysis of Dependent Variables $\quad 41$

Mean Performance for Dependent Variables across

$\begin{array}{ll}\text { Stimulus Conditions } & 48\end{array}$

Effect Size of the Intervention across Stimulus Conditions $\quad 50$

Social Validity $\quad 54$

\section{CHAPTER 5}

DISCUSSION 56

Limitations of the Current Study and Suggestions for Future Research 60

$\begin{array}{ll}\text { Implications for Practice } & 61\end{array}$

$\begin{array}{ll}\text { Conclusion } & 62\end{array}$ 


\section{APPENDICIES}

A Teacher Interview Form 64

B Parent Interview Form 65

C Example of a Storyboard 66

D Steps for Creating the VSM 67

$\begin{array}{lll}\text { E Interval Data Sheet } & 68\end{array}$

F Treatment Fidelity Check (David) 69

G Treatment Fidelity Check (Nate) 70

$\begin{array}{ll}\text { REFERENCES } & 71\end{array}$

$\begin{array}{ll}\text { VITA } & 87\end{array}$ 


\section{LIST OF TABLES}

Page

Table 1: Mean occurrence of dependent variables for David 49

Table 2: Mean occurrence of dependent variables for Nate 50

Table 3: PEM calculations for David 52

Table 4: PEM calculations for Nate 


\section{LIST OF FIGURES}

Figure 1: Process for Making a Comorbid Diagnosis

Figure 2: Diagrammatic Representation Between Behavioral Influences and Resulting Self-Regulation

Figure 3: Intervention Procedures

Figure 4: Multiple Baseline across Stimulus Conditions for David 


\begin{abstract}
This study evaluated the efficacy of a video self-modeling and functional behavior assessment intervention on a traditionally under-represented population. Students diagnosed with Autism Spectrum Disorder (ASD) and Intellectual Disabilities (ID) are prone to higher rates of aggressive behavior that can be resistant to treatment. Under the frameworks of Behaviorism and Social Cognitive Theory an intervention was developed to decrease aggressive behaviors and increase self-regulated behavior. A multiple baseline design across stimulus conditions with inter-subject replication was conducted to explore the effects of the intervention. Data was collected on both the rate of aggressive behaviors and the use of a replacement behavior which fostered socially appropriate self-regulation. The data indicate that both participants demonstrated a decrease in aggressive behavior immediately following intervention across all stimulus conditions. Data collected on the replacement behavior indicated a change from baseline to intervention but results differed across participants.
\end{abstract}




\section{CHAPTER ONE INTRODUCTION}

Autism Spectrum Disorders (ASD) comprise a heterogeneous set of neurodevelopmental disabilities characterized by marked deficits in social communication and restricted patterns of behavior (American Psychiatric Association [APA], 2013). Social communication deficits can occur in the areas of language, symbolic communication, understanding other people's perspectives, attitudes, and behaviors (Baron-Cohen, 1985, 1988). Restricted patterns of behavior can result in impaired mental flexibility, attention, and behavior regulation (Carlson \& Moses, 2001; Mazefsky, et al., 2013). Taken together, these neuro-developmental deficits often lead to emotions such as anger, frustration, loneliness, and anxiety that can result in behavioral responses that are difficult to manage (Corbett \& Abdullah, 2005; Gotham, Brunwasser, \& Lord, 2015; Lovass, Koegel, \& Schreibman, 1979; Matson \& Jang, 2014; Matson \& Shoemaker, 2009).

Emotions emanate from an individual's overall evaluation of a stimulus (Beck, 2011; Mazefsky, et al., 2013; Pouw, Reiffe, Oosterveld, Huskens, \& Stockm, 2013). A complex processing system capable of reasoning, rationalizing, and labeling is responsible for mediating these emotional responses (Beck, 2011; Hariri, et al., 2000; Westen, Blagov, Harenski, Klits, \& Hamann, 2006). When an individual's ability to evaluate stimulus is compromised, as it can be in individuals with ASD (e.g., mental inflexibility, impaired communication), maladaptive emotional responses are likely to result in (Goldin, Matson, \& Cervantes, 2014; Matson \& Adams, 2014; Patel, Day, Jones, \& Mazefsky, 2016; Pine, Guyer, Goldwin, Towbin \& Leibenlufte, 2008). Maladaptive responses such as aggression, vary in frequency and intensity and may persist over the 
lifetime (Gelbar, Anderson, McCarthy, \& Buggey, 2012; Matson \& Adams, 2014; Matson \& Shoemaker, 2009; Storch et al., 2012).

ASD and Intellectual Disabilities (ID). The highest rates of challenging behaviors have been observed in those who have both ASD and an intellectual disability (ID) (Carroll, et al., 2014; Goldin, Matson, Cervantes, 2014; Gotham, Brunwasser, \& Lord, 2015; Jang, Dixon, Tarbox, \& Granpeesheh, 2011; Matson \& Shoemaker, 2009; Rojahn, et al, 2010; Storch, et al., 2012). In fact, according to a 2012 report from the Center for Disease Control (CDC) among those identified with ASD, approximately onethird also had an intellectual disability. An ID refers to deficits in two areas: intellectual and adaptive functioning (APA, 2013; CDC, 2012). Intellectual functioning includes deficits in reasoning, problem-solving, abstract thinking, academic learning, and learning from experience; whereas adaptive functioning refers to the ability to meet developmental and social standards for personal independence and social responsibility (APA, 2013).

A comorbid diagnosis of ASD and ID is considered if there are delays in one or more of the core ASD symptoms are more severe than would be expected for the developmental level (CDC, 2012). The process of making a comorbid diagnosis is outlined in Figure 1. When ASD and ID coexist, symptoms of ASD appear to be exacerbated (e.g., severe deficits in social communication, severe deficits in adaptive behavior, and severely restricted patterns of behavior, interests, and activities (Goldin, Matson, \& Cervantes, 2014; Gotham, Brunwasser, \& Lord, 2015; Matson \& Shoemaker, 2009). Often, for individuals with ASD and ID, maladaptive behaviors are highly entrenched, occur at high rates, and are difficult to manage (Matson \& Adams, 2014; 
Pedersen, et al., 2017; Reese, Richman, Belmont, \& Morse, 2005). In fact, for individuals with ID and ASD there is a poorer prognosis for those on intensive behavior plans (Kanne \& Mazurek, 2011; Matson \& Shoemaker, 2009; Rojahn, et al., 2010).

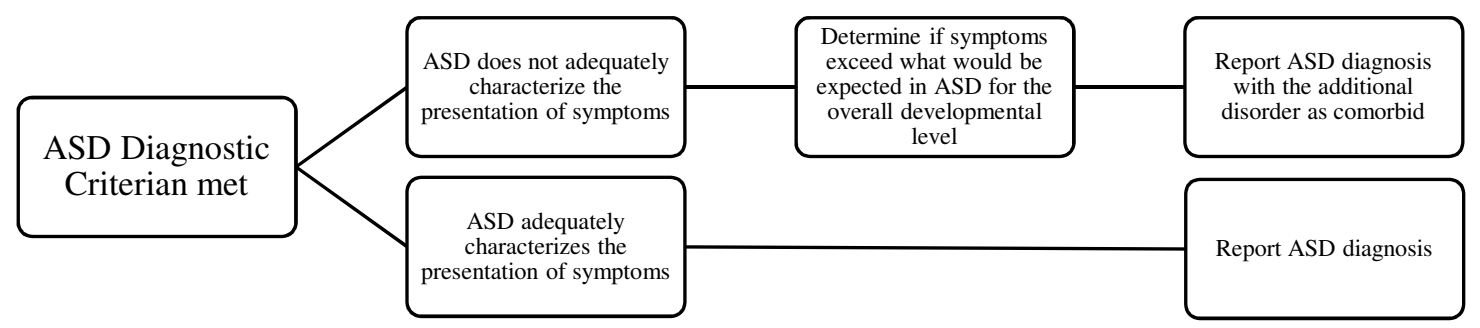

Figure 1. Process for Making a Comorbid Diagnosis (Adapted from CDC) Note. ASD = Autism Spectrum Disorder.

Given the poorer prognosis, antipsychotic medications are often used to treat aggressive behavior. The most commonly used drugs to treat aggression and self-injury approved by the Federal Drug Administration (FDA) are risperidone and aripiprazole (Carroll, et al., 2014; Siegel, 2012). While pharmacological treatments are an option, they remain controversial due to potential long-term side effects and questionable effectiveness. Furthermore, pharmacology treats symptoms by inhibiting receptors in the brain but fail to address the person's evaluation of external stimuli that contribute to maladaptive responses. Consequently, pharmacological treatments should occur alongside behavior interventions designed to address the purpose for aggressive behavior (Brosnan \& Healy, 2011; Matson \& Adams, 2014; Matson \& Jang, 2014; Roth, Gillis, \& 
DiGennaro-Reed, 2013; Siegel, 2012). Many of these behavior interventions are delivered under the guidance of a therapist (e.g., psychiatrist) or within the school setting.

\section{School Based Treatments for Aggression}

Most school-based interventions to treat aggressive behaviors draw from principles of behaviorism (Carroll, et al., 2014; Matson, 2009; Scheuermann \& Hall, 2016). In behaviorism, learning is the process of forming associations between stimuli and responses (Carroll, et al., 2014; Fischer, Groff, \& Roane, 2011; Scheuermann \& Hall, 2016; Schunk, 2012; Skinner, 1953). This theory suggests that features of the physical environment (e.g., stimuli, situations, events) serve as cues for responses or behaviors (Fischer, Groff, \& Roane, 2011; Schunk, 2012; Skinner, 1953, 1973). Features of the physical environment, are considered reinforcing or punishing to the observer, therefore patterns of behavior, in a stimulus-response situation, are either strengthened or weakened (Skinner, 1953, 1973). In particular, when the outcome is reinforcing, the connection is strengthened; whereas, when a connection between a stimulus and a response is punishing the connection is weakened (Schunk, 2012; Skinner, 1953, 1973; Watson, 1928). For example, if a student earns praise for good behavior (a reinforcing stimulus) they will likely continue to engage in good behavior (response). If a student loses points for bad behavior (punishing stimulus) he will likely change his behavior (response).

According to behaviorism, operant conditioning is the mode in which behavior can be intentionally modified (Baer, Wolf, and Risley, 1968; Skinner, 1953, 1973; Schunk 2012). The basic operant conditioning model involves the relationship between a descriptive stimulus (antecedent), a response (behavior) and the reinforcing stimulus 
(consequence). Using this model, situations are contrived to where the descriptive stimulus (antecedent) is altered in order to influence the response (behavior) while the, consequence is observed. The process of observing behavioral relationships in an operant conditioning model is called a functional analysis. The most common application of functional analysis procedures is Applied Behavior Analysis (ABA).

Applied Behavior Analysis (ABA) Procedures. Applied Behavior Analysis (ABA) includes a wide range of strategies focused on observable interactions between the individual and the physical environment (Baer, Wolf, and Risley, 1968; Fisher, Groff, \& Roane, 2011). Those who have used ABA have developed successful strategies and measurement techniques based upon operant conditioning to modify many types of behavior, including the reduction of aggressive behavior in individuals with and without ASD (Baer, Wolf, and Risley, 1968; Fisher, Groff, \& Roane, 2011; Hanley, Iwata, \& McCord, 2003; National Research Council [NRC], 2001; National Institute of Mental Health [NIMH], 2008; Rosenwasser \& Axelrod, 2001; Roth, Gillis, DiGennaro-Reed, 2014; Westling, 2015). All ABA interventions are highly systematized, many of which require a professional trained in the technique to guide implementation (e.g. Board Certified Behavior Analysist [BCBA]). When using ABA to modify any behavior, including aggression, the first step involves an analysis of the target behavior to identify the purpose of the behavior. The most commonly used approach used to do this is through a functional behavior assessment.

Functional Behavior Assessment. A functional behavior assessment is used to identify antecedents and consequences surrounding a behavior and allow for the development of a function-based intervention (Baer, Wolf, \& Risley, 1968; Fisher, Groff, 
\& Roane, 2011; Hanley, Iwata, \& McCord, 2003; Iwata, Kahng, Wallace, \& Lindberg, 2000; Westling, 2015). There are two data collection methods used in a FBA data; direct (e.g., observations) and indirect methods (e.g., teacher/caregiver interviews). Direct observations use Antecedent-Behavior-Consequence (ABC) data collection to analyze target behaviors under naturalistic conditions. First described by Bijour, Peterson and Ault (1968), ABC data collection involves collecting information on the events that precede (antecedent) and follow (consequence) a target behavior (Bijour, Peterson, \& Ault, 1968; Iwata, et al., 2000). ABC data collection has become a common method used to capture behavioral sequences for the purposes of developing a hypothesis about target behaviors particularly in context (Iwata, et al., 2000).

Bijour and colleagues' seminal work (1968) suggest that ABC data, is prone to low fidelity due to its open-ended nature and should therefore be used in conjunction with other functional assessment methods. For this reason, indirect methods such as teacher or caregiver interviews, are often used in conjunction with $\mathrm{ABC}$ data collection to develop a hypothesis about behavior function (Iwata, et al., 2000). Indirect methods involve soliciting anecdotal information from individuals who have witnessed the target behavior. These interviews are typically structured, using checklists, rating scales, or questionnaires (Iwata, et al., 2000).

$\boldsymbol{A B A}$ Intervention. Once the function of the behavior has been identified via a FBA, a treatment (or intervention) is introduced. The treatment is designed to teach a socially appropriate reinforcing condition, referred to as a replacement behavior. During treatment either the antecedent stimulus or consequence is altered in order to influence the student's response or behavior (Scheuermann \& Hall, 2016). The mechanism of 
change in $\mathrm{ABA}$ treatments involves a number of teaching strategies including: positive reinforcement, negative reinforcement, punishment, extinction, stimulus control, modeling, and shaping (Bijour, Peterson, \& Ault, 1968; Iwata, et al., 2000; Scheuermann \& Hall, 2016). These strategies vary in frequency and duration, based on individual needs but all require modifications to the physical environment in order to produce change.

\section{Rationale for Current Study}

Within the k-12 school setting, aggressive behavior has been identified as the cause for the greatest loss of instructional time, reduced opportunities for independent functioning and interpersonal relationships, and restrictive placements (Brosnan \& Healy, 2011; Farmer \& Aman, 2011; Farmer, et al., 2015; Jang et al., 2011; Kanne \& Mazurek, 2011; Matson \& Adams, 2014). According to numerous research studies, ABA interventions have been demonstrated to be effective in reducing aggressive behavior, even in individuals with ASD and ID (Brosnan \& Healy, 2011; Braithwaite \& Richdale, 2000; Charlop-Christy \& Haymes, 1996; Durand, 1999; Dooley, Wilczenski, \& Torem, 2001; Falcomata, Roane, Muething, Stephenson, \& Ing, 2012; Foxx \& Garito, 2007; Foxx \& Meindi, 2007; Frea, Arnold, \& Vittimberga, 2001; Heckaman, Alber, Hooper, \& Heward, 1998; Kern, Carberry, \& Haidara, 1997; Mueller, Wilcynski, Moore, Fusilier, \& Trahant 2001; Schindler \& Horner, 2005). However, despite the positive outcomes of ABA interventions, high rates (over 50\%) of aggressive behavior have been reported across large samples of individuals with ASD (Bronsard, Botbol, \& Tordjman, 2010; Farmer and Aman, 2011; Farmer, et al., 2015; Kanne \& Mazurek, 2011; Mazurek, Kanne, \& Wodka, 2013; McTiernan, Leader, Healy \& Mannion, 2011; Medeiros, 
Kozlowski, Beighley, Rojhan, \& Matson, 2012; Murphy, Healy, \& Mannion, 2009).

Detrimental effects and high rates of aggressive behavior demonstrate that more work in the area is clearly needed. (Brosnan \& Healy, 2011; Jang, et al., 2010; Matson \& Jang, 2014; Matson \& Adams, 2014).

According to behaviorism, an individual decides which behaviors to regulate based upon consequential reinforcing or punishing stimuli. This learning theory suggests that internal processes (e.g., thoughts, beliefs, feelings) are not necessary to explain learned behavior. It's possible that both environmental contributors to behavior (e.g., stimulus-response) and internal contributors to behavior (e.g., thoughts, feelings, and beliefs) could be combined to create a new intervention and address the contradiction in the literature. As Albert Bandura (1978) states,

In their transactions with the environment, people are not simply reactors to external stimulation. Cognitive factors partly determine which external events will be observed, how they will be perceived, whether they have any lasting effects, what valence and efficacy they have, and how the information they convey will be organized for future use (p. 345).

\section{Purpose of the Study}

The purpose of this study is to test the effectiveness of an intervention that not only focuses on behavioral responses to the physical environment but also incorporates psychological implications on behavior. Combining behavior-based strategies, specifically, functional behavior assessments (which control for external consequences) with a second mechanism, namely video self-modeling (VSM), to modify internal 
consequences could be more effective at reducing aggressive behavior compared to either strategy in isolation. 


\section{CHAPTER TWO}

\section{LITERATURE REVIEW}

Video modeling as a way to show a desired behavior has been in existence in the research literature for over 40 years (Creer \& Miklich, 1970; Dowrick, 1999, 2012; Hitchcok, Dowrick, \& Prater, 2003; Hosford, 1981; Wert \& Neisworth, 2003). In the current literature, there are two main ways of categorizing video modeling: video modeling (VM) and video self-modeling (VSM). Video modeling (VM) consists of showing a person a video of someone performing a targeted skill (Cihak \& Schrader, 2008; Gelbar, et al., 2012) whereas in VSM, the performer is the intended viewer. Interestingly, the very first use of the self as a model, "self-modeling," was introduced in a study conducted by Creer and Miklich in 1970 (cited in Hitchcock, Dowrick, \& Prater, 2003). The participant was a 10-year-old "asthmatic boy" who exhibited severe "temper tantrums." Through the use of a reversal design, it was demonstrated that the boy displayed socially appropriate behavior when shown a video of himself exhibiting socially appropriate behavior and displayed tantrum behavior when shown a video of himself exhibiting tantrum behavior. The authors concluded that using the self-as-model within video modeling can be a highly effective approach to modify behavior.

Since that study, numerous studies involving some form of modeling via a video format have been conducted. Overall, the findings support the use of VM and VSM as a means to change behavior (Bellini \& Akullian, 2007; Delano, 2007; Rayner, Denholm, \& Sigafoos, 2009; Wang \& Spillane, 2009). Although both forms are evidence-based, the focus of this study is on VSM. Unlike VM, VSM incorporates a theoretical perspective 
that goes beyond a predominantly behavioral model that, as suggested may not necessarily have the desired effect of reducing unwanted behaviors, particularly aggressive behavior (Ayres, Davis, \& Mason, 2016; Belllini \& Akullian, 2007; Buggey, 2005; Creer \& Miklich, 1970, Dowrick, 1999, 2012: Gelbar, et al., 2012). While to some the model may seem a minor difference, VSM explicitly draws upon Bandura's work (1977, 1989, 1997) which suggests people learn best from models that most closely resemble themselves and having oneself as the model optimizes this factor (Bandura, 1969, 1977, 1982, 1997; Buggey, 2005, 2009; Dowrick, 1999; 2012; Gelbar, et al., 2012). The remainder of this chapter will (a) demonstrate how VSM is connected to theory, (b) discuss the strength of using VSM as an intervention for reducing aggressive behavior in individuals with ASD and ID, and (c) outline the purpose and rationale for the current study that combines the use of VSM and functional behavioral assessment.

\section{Social Cognitive Theory}

Albert Bandura's (1989, 1997, 2001) Social Cognitive Theory (SCT) suggests that human behavior is dependent upon a triadic model of influence. His theory was radically different from competing theories at the time that suggested human behavior is solely influenced by the reinforcing and punishing consequences within the environment (Schunk, 2012). In SCT, behavior (e.g., performance), personal factors (e.g., expectations, self-beliefs, and goals), and environmental influences (e.g., modeling, instruction, and social persuasion) operate reciprocally as mediators of human thoughts, affect, and action (Bandura, 1986, 1977, 1989) (see Figure 2 for an overview of the model). According to SCT once a personal belief system is established by way of the 
triadic model of influence, human behavior becomes self-regulated (Bandura, 1991;

Schunk, 2012).

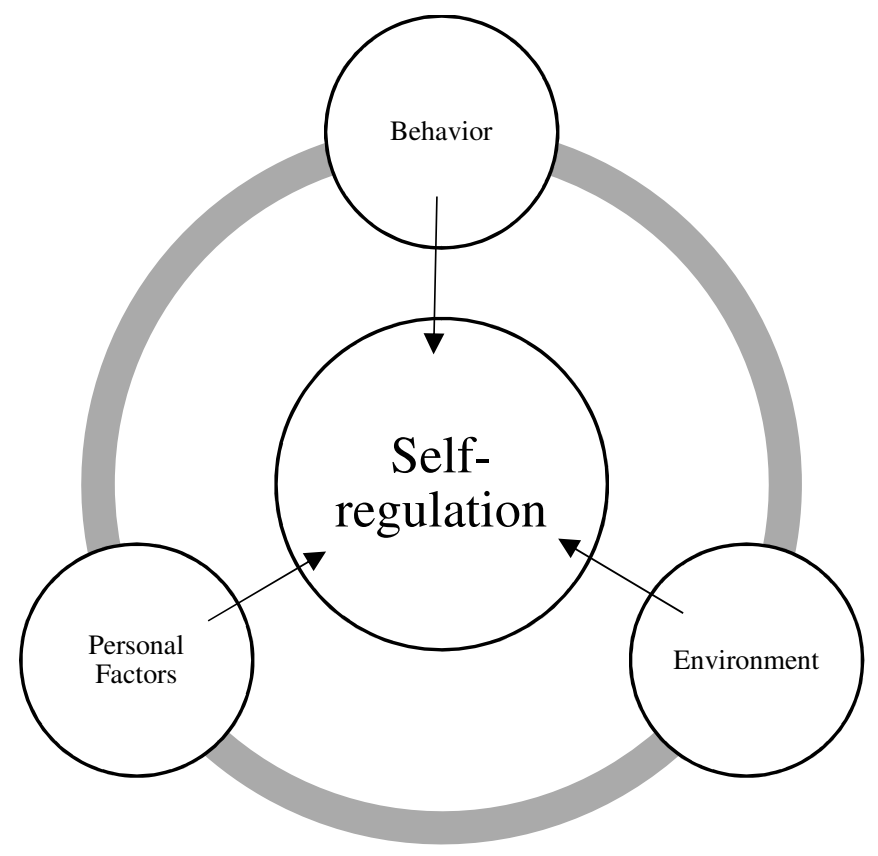

Figure 2: Diagrammatic Representation Between Behavioral Influences and Resulting Self-Regulation (adapted from Bandura, 1986).

According to SCT, self-regulation is an internal process by which individuals maintain their personal belief system by way of initiating and sustaining behaviors and cognitions (Bandura, 1977, 1982, 1997, 2012). SCT emphasizes that self-observation, self-judgement, and self-reaction impact self-regulated behavior (Schunk, 2012). Mechanisms to change self-regulated behavior include goal setting, self-efficacy, and self-evaluations (Schunk, 2012). This view of self-regulation differs from a behaviorist approach which emphasizes that self-instruction and self-reinforcement impact selfregulated behaviors. Under a behaviorist paradigm an individual decides which new 
behaviors to self-regulate based upon stimuli in the physical environment following a performance (Schunk, 2012).

Self-regulation is important because "neither intention nor desire alone has much effect if people lack the capability for exercising influence over their own motivation and behavior" (Bandura, 1991, p. 249). As an illustration, if a student tears up her paper (e.g., behavior) every time she is under stress (e.g., personal factor), and the stressful condition is removed every time she tears up her paper (e.g., environment), her reaction to stress will become self-regulated (e.g., "if I tear up my paper, my stress will be alleviated"). When patterns of self-regulated behaviors are challenged, new behaviors can emerge (Bandura, 1989, 1991). Bandura (1986) states that when "discrepancies between a performance and the standard against which it is measured, activate evaluative selfreactions, which serve to influence subsequent behaviors" (p. 20). Thus, when behavior is modified, as it is in learning, an individual's personal belief system and patterns of self-regulation have been altered. For instance, if a student believes that they are not good at math (e.g., personal factors), they may expend little effort to achieve mathematically (e.g., self-regulated behavior). However, if that same student is taught to work on small tasks and monitor their success (e.g., environment), the self-monitored progress (e.g., personal factors and behavior) may result in sustained effort for learning (e.g., self-regulated behavior) (Bandura, 1989, 1991; Schunk, 2012).

Learning under this framework requires that the learner be involved in the process by way of "enactive" and "vicarious" situations (Bandura, 1965, 1977, 1984; Schunk, 2012). Enactive learning is the act of learning by observing models, whereas vicarious learning is the act of learning through experiencing (Bandura, 1965, 1977). Enactive 
learning is dependent upon environmental cues whereas vicarious learning is dependent upon self-evaluation (Bandura, 1984, 1989). The strength of enactive and vicarious learning is moderated by two important variables: self-efficacy and observational learning.

Self-efficacy. Bandura (1977) defines self-efficacy as the belief in one's personal abilities to accomplish a goal. Bandura suggests that a person's expectations of the outcome directly impact both task initiation, and the ability to cope with the event or task (Bandura, 1977, 1982). Furthermore, self-efficacy impacts a person's willingness to attempt a task. As an illustration, people tend to avoid situations they may find threatening or overwhelming, whereas they are more likely to engage in situations they find safe or encouraging (Bandura, 1977, 1982, 1984, 1997). Therefore, increases or decreases in self-efficacy impact personal factors which in turn influence behavior, according to the triadic model.

Observational learning. The most common form of observational learning is modeling (Bandura, 1965, 1975; Schunk, 2012). In modeling, the viewer observes a situation and is motivated to display new patterns of behavior (Schunk, 2012). Observational learning through modeling is a complex process involving several cognitive processes: (1) attention, (2) retention, (3) motivation, and (4) reproduction. First, the viewer must attend to the model demonstrating the behavior. Ideally, a model is similar in age, sex, or status to the observer (Ayres, Davis, \& Mason, 2016; Bandura, 1969, 1977, 1982, 1997; Dowrick, 1999; Schunk, 2012). Second, the observation must be within the viewer's capability to retain or remember the behavior of the model (Bandura, 1997; Dowrick, 1999, 2012). Third, the viewer must be motivated to copy the 
behavior (Bandura, 1977; 1989). Fourth, the viewer must be able to reproduce the behavior (Bandura, 1977, 1989; Dowrick, 2012).

In summary. According to Bandura's theory, existing patterns of behavior can change through self-efficacy and modeling. Increases in self-efficacy and opportunities for self-evaluations have the ability to modify current patterns of self-regulated behavior which would allow for new behaviors and cognitions to be adopted. Video self-modeling is one method that supports these elements of change and has the potential to modify aggressive behaviors of students with ASD and ID through improved self-regulation skills.

\section{Overview of Video Self-Modeling (VSM)}

There are three main features of VSM. First, the model in the video is the intended observer (Buggey, 2006; Dowrick, 1999, 2012; Gelbar, et al., 2012). Second, the skill must be in the observer's behavior repertoire (Bandura, 1965; Bellini \& Akullian, 2007; Buggey, 2006; Dowrick, 1999, 2012; Corbett \& Abdullah, 2005; Dowrick \& Biggs, 1983; Gelbar, et al., 2012; McCoy \& Hermansen, 2007). Third, the viewer must perceive value in the goal (Bellini \& Akullian, 2007; Dowrick, 1999, 2012, Prater et al., 2012).

In a VSM intervention the intended viewer demonstrates a target behavior (Bandura, 1986, 1989; Buggey, 2006; McCoy \& Hermansen, 2007). The target behavior is typically something that is either inconsistently being demonstrated (e.g., a performance deficit) or one that is slightly outside of their current capabilities (e.g., a performance deficit) (Buggey, 2006; Dowrick 1983, 1999, 2012). For example, if a student inconsistently walks in a line with his class in the hallway, an appropriate VSM 
would deficit the student walking in a line down the hallway and receive a desirable consequence upon completion (e.g., verbal praise).

To create the videos, the student is prompted (verbal, visual, and/or physical) through a series of replacement behaviors (e.g., walk in a line). During the editing process, all errors, prompts, and extraneous footage is taken out leaving only depictions of positive targeted behaviors (Bellini \& Akullian, 2007; Dowrick 1999; Gelbar, et. al., 2012; McCoy \& Hermansen, 2007). In the final product, the viewer sees themselves performing the target skill at mastery level (Buggey, 2006, 2009; Dowrick, 1997, 1999, 2012). The viewing of the VSM allows the individual opportunities to self-evaluate and improved self-efficacy which have the power to modify self-regulated behavior.

Connection to SCT. VSM draws from SCT in that it provides the learner both enactive and vicarious experiences specific to an academic, behavioral, adaptive, communicative or social need (McCoy \& Hermansen, 2007). Enactive learning occurs as the observer witnesses the sequence of actions necessary to perform a skill; vicarious learning is stimulated because the model is the intended viewer. The act of viewing a VSM allows the individual an opportunity to believe in the possibility that he can perform the sequence of actions portrayed, thus increasing self-efficacy (Buggey 2009; Dowrick, 2012; Gelbar, et al., 2012). The increase in self-efficacy typically results in expended effort and persistence to accomplish the depicted task (Bandura, 1997; Bellini \& Akullian, 2007; Corbett \& Abdullah, 2005; Dowrick \& Biggs, 1983; Gelbar, et al., 2012; Howsford, 1981; Schunk, 1989).

There are four cognitive processes (attention, retention, motivation, and reproduction) are accounted for in a VSM intervention. First, having the model be the 
intended viewer optimizes the chances for attention and internalization (Ayres, Davis, \& Mason, 2016; Dowrick, 1999, 2012). Second, the videos in VSM are typically short and personally connected to a situation that the viewer is experiencing, therefore increasing the likelihood that the information be retained (Buggey, 2006; Dowrick, 1983). Motivation in a VSM can come in many forms such as the self being the model, seeing a desired behavioral outcome (e.g., receiving a desirable object) and/or by adding reinforcing elements to the video (e.g., visual and auditory sound effects) (Buggey, 2006). Lastly, given that the model is the viewer, it demonstrates that the target behavior is able to be reproduced (Dowrick, 1999, 2012).

\section{ASD and School Based Video Self-Modeling (VSM)}

VSM has been used as a school-based intervention for people with ASD to address the following : adaptive behavior (Cihak \& Schrader, 2008; Cihak, Fahrenkrog, Ayres, \& Smith, 2010), compliance training (Buggey, 2005; Coyle \& Cole, 2004; Lang, et al., 2009), academic skills (Burton, Anderson, Prater, \& Dyches, 2013; Hart \& Whalon, 2012; Marcus \& Wilder, 2009; Schatz, Peterson, \& Bellini, 2016), social skills (Bellini, Akullian, \& Hopf, 2007; Boudrea \& Harvey, 2013; Buggey, Toombs, Gardener, \& Cervetti, 1999; Buggey, Hoomes, Sherberger, \& Williams, 2011; Hart \& Whalon, 2012; Wert \& Neisworth, 2003), and emotional recognition (Bernad-Ripoll, 2007). Overall, research has demonstrated that VSM meets the criteria as an evidence-based intervention for individuals with ASD, often producing substantial positive changes in student behavior without the need for intensive services (e.g., one on one therapy in a restrictive placement) (Bellini \& Akullian, 2007; Bellini, Gardner, Hudock, \& Kashima- 
Ellingson, 2016; Dowrick, 2012). Further, these studies report high levels of engagement for students (e.g., reports that the student's enjoy seeing themselves in the video).

Despite VSM's success for students with ASD only four studies have focused on the use of VSM for students with ASD and ID. Before summarizing the literature, it is important to note that classification for this population (ASD and ID) is vague. For example, in one situation, a VSM study reported an ASD description, but did not indicate an IQ score (e.g., Buggey, Hoomes, Sherberger, \& Williams, 2011). While others reported both ASD descriptors and IQ scores (e.g., Cihak \& Schrader, 2008; Cihak, et al., 2010; Coyle \& Cole, 2004). Changing diagnostic criteria could account for such variance participant classification. For instance, improved screening methods may have provoked? Resulted in diagnostic substitution where individuals who were once diagnosed as having ID and are now diagnosed as having severe ASD (Matson \& Shoemaker, 2009; Pedersen, et al., 2017). Discrepant overlap between ASD and ID have been found in several prevalence studies (Pedersen, et al., 2017). For the purposes of the following review participants that meet either of the following criteria were included for discussion: (1) a score on a diagnostic measurement that places them in a "severe ASD" category; (2) and/or a diagnosis of ASD with an "age equivalent IQ score" or IQ score that indicates an ID.

VSM for Students with Severe ASD and ID. Cihak and Schrader's (2008) study compared VMs and VSMs for the effects of teaching chained vocational tasks to students with ASD and ID. Four high school students (age range 16 to 21 years) were diagnosed with severe ASD according to diagnostic measurements (Childhood Autism

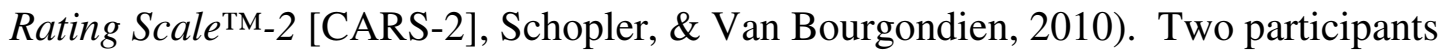


had IQs of 45 and 50 suggesting moderate ID (Developmental Profile ${ }^{\mathrm{TM}}-2$ [DP-2], Alpern, 2007). The other 2 participants had IQs of 30 and 35 suggesting severe ID. The purpose of each video was to show the participant depicting one of four vocational tasks (e.g., making a photocopy) ranging from 10 to 12 steps to complete the task. The VSMs ranged from 34 to 103 seconds and verbal praise was embedded in the video. An alternating treatments design was utilized where each participant had a VM condition and a VSM condition. Event recording was collected as each step of the chained task was marked "completed" or "not completed." According to the results, two students reached acquisition at a faster rate in the VSM condition and the other two participants showed no difference. Overall, the authors suggest that the videos positively influenced the participants' initiation to start a task and lessened the duration of task completion.

Cihak and colleagues (2010) examined the use of hand-held devices to deliver VSM instruction to improve transitioning within the school building. The participants were four elementary school students (age range 6-8 years) diagnosed as having severe ASD according to diagnostic measurements (CARS-2). Three students had an IQ range of 45-50, suggesting moderate intellectual disabilities (DP-2). One student had an IQ of 35 that indicated a severe intellectual disability (DP-2). All students had difficulty transitioning independently within the school building. Out of four participants, two exhibited aggression during transitions, one ran away from the teacher, and one would sit on the floor and refuse to move. Ten specific transitions were targeted and individualized per student needs. Transitions included the following: bus to classroom; classroom to music room; and bathroom to classroom. Each video clip lasted two to five minutes depending on the distance of the transition and verbal praise was embedded in the videos. 
The participants' viewed the clips on an iPod prior to performing the transition. A reversal $(\mathrm{ABAB})$ design was used where the VSM was either presented or not presented prior to transitioning. Event recording was collected and each transition was marked "successful" or "not successful." Results indicated that all students improved in independent transitions overall.

Coyle and Cole's (2004) study aimed to decrease the off-task behavior of three children with ASD (age range 9-11 years). Two of the students were diagnosed as having severe ASD and the third was moderately impacted according to diagnostic measurements (not reported). The student with moderate ASD was described as having a comorbid moderate intellectual disability according to psychological measures (not reported). The two students with severe ASD had comorbid intellectual disabilities according to age equivalents ( 2 years 10 months; 3 years one month). The dependent variable, "off-task behavior" was the same for all participants and was defined as, looking around at other children, fiddling with a pencil or other objects, rolling items from the desk, inspecting objects and other students at close proximity, touching other students, staring blankly, or leaving their seats. The videos depicted the students engaging in "on-task behavior" (e.g., sitting at their desk, listening to the teacher, refraining from touching objects not related to the activity. The videos were three minutes in length and included behavioral descriptions and praise. After viewing the videos once every morning, each student had a visual reminder to assist in remembering the video and marked a checklist to monitor their behavior during the activity. Single case design was the methodology in this study however, two case studies utilized a reversal (ABAB) design and the third followed a withdrawal (ABACA) design. For all 
three studies, off-task behavior was measured using time sampling recording (30 observation intervals followed by a five-minute break). The results indicate that the combination of VSM and a self-monitoring tasks were effective at reducing off-task behaviors.

Buggey, Hoomes, Sherberger, and Williams (2011) used VSM to teach social skills to pre-school participants. Four students (age range 3 to 4 years) participated in the study. Three were diagnosed as having severe ASD and one was labeled as having moderate ASD according to diagnostic measurements (CARS-2) but no IQ scores were reported. Pre-requisite skills for a VSM intervention were tested by showing each student a video or picture of themselves on a large screen and recording responses. The videos were 2.5 to 3.5 minutes in length and featured each participant social interacting with a peer. Reinforcing phrases (e.g., "great job”), music, and images were added to the videos. Additionally, verbiage to label the behavior (e.g., "Let's watch Lucy play with her friends!") was added to the videos. A multiple baseline across participants was used to determine the effect of the intervention. Frequency data on the dependent variable (social interactions) was collected during 15-minute observations. Participants made gains in social interactions.

Taken together, these four studies clearly demonstrate that VSM can be used with individuals with ASD and ID as a way to reduce some type of unwanted behavior. Further, all of the studies were able to modify behaviors in the majority of participants. Despite these positive findings, no study focused specifically on VSM's potential to reduce aggressive behavior in this population. Although Cihak and colleagues (2010) indicate that two students in their study displayed aggressive behavior, this was not the 
primary variable targeted for change. Instead, they focused on improving "successful" transitions therefore no measurements on the rate of aggressive behavior were collected and the conclusion regarding VSM's effectiveness to reduce aggressive behavior is merely inferred.

In addition, these studies provide invaluable insight into how VSM can be used with individuals who have comorbid ASD and ID in the following areas: (1) video length, (2) engagement, and (3) response to prompting. First, the VSM length of the four studies ranged from 30 seconds to five minutes depending on the task. Brevity or attention to cognitive load may be an important factor when considering attention to the VSM. Second, all four studies used a method to optimize engagement in the videos (e.g., visual and/or auditory effects, verbiage to label the behavior). Individuals with ASD and ID have severely restricted attention and interests, therefore the additional images, sounds, and verbiage may have improved retention and comprehension. Finally, all of the students were prompted through the target behavior in order to create the videos thus, ensuring that the skill itself is within their capabilities and thus able to be reproduced.

VSM to Treat Aggressive Behavior. Of the available research to-date, only one study has focused specifically on reducing aggressive behavior. Buggey (2005) used video self-modeling (VSM) to reduce instances of pushing displayed by a pre-school student who was moderately impacted by ASD. The young boy had deficits in expressive and receptive language and he often grabbed his peer's cheeks and then pushed him or her away. Buggey (2005) reported that after viewing the video one time, the child's pushing behavior occurred only once and was not reported during the rest of the intervention or maintenance condition. The results of this study are astounding 
considering the minimal invasiveness (e.g., delivered one time daily with minimal supervision from a professional) and immediate behavioral changes. Similar to other school-based interventions for aggressive behavior, the VSM intervention redirected an aggressive behavior with a socially appropriate behavior. Additionally, this intervention offered a chance for self-evaluation and improved self-efficacy as the child viewed himself appropriately interacting. Therefore increasing the likelihood of impacting selfregulated behavior.

Despite the promising results, limitations to this study need to be acknowledged. First, Buggey (2005) treated aggressive behaviors without the use of a functional behavior assessment. Therefore, the behavior function and appropriate replacement behavior were merely assumed. Without a confirmed hypothesis of behavior function, it is not possible to ascertain that the replacement behavior depicted in the video eradicated the aggression. For instance, it is possible that the novelty of the intervention decreased the behavior in the depicted situation, but the purpose or satisfying consequence of the aggression was still unmet. If the target behavior in a VSM is derived from a functional behavior assessment, one can ensure that it is consequentially satisfying for the learner. Second, as there was only one participant in one condition (i.e., lining up for recess) further replication is required to determine if this is a viable means to modify aggressive behavior in other settings/conditions. Third, Buggey (2005) reported that the student was moderately impacted by ASD. This study did not include individuals with comorbid ASD and ID or those severely impacted by ASD.

\section{Purpose of the Current Study}


Research indicates that individuals with ASD and ID are most likely to engage in aggressive behaviors that can be resistant to treatment (Matson et al., 2008; Matson \& Shoemaker, 2009; O’Brien \& Pearson, 2004; Storch et al., 2012). A need exists for the development of interventions that can overcome high rates of aggressive behavior in this population. One possible approach is a treatment that combines both VSM and functional behavior assessment to modify aggressive behavior. Functional behavior assessments (e.g., screening tools and direct observations) have been widely used as a way to analyze aggressive behaviors for individuals with ASD, whereas VSM interventions have been demonstrated to work among those with ASD and ID. However, no study has combined the use of functional behavior assessments and VSM for those with ASD and ID. It is possible that the strengths of these interventions can be combined to make a comprehensive whole that could possibly overcome high rates of aggression and add to the literature base for this population.

To illustrate, the strength of VSM is that it provides the viewer an opportunity for self-evaluation and increased self-efficacy as he/she sees themselves successfully performing a desired behavior. Whereas, the strength of functional assessment is to determine the specific environmental consequence for a behavior function, which allows for an equally reinforcing socially appropriate behavior to be taught as a replacement. When combined, the intervention has the potential to reduce unwanted aggressive behaviors by appealing to both internal (e.g., self-evaluation, self-efficacy) and external factors (e.g., environmental stimuli, exposure to modeling) responsible for self-regulated behavior. 
Therefore, the purpose of the following study is to test an intervention that combines both VSM and functional assessment designed to decrease aggressive behavior and improve self-regulated behavior by using a replacement behavior. By doing so, this study extends literature in both the fields of analytic behavior and VSM research. This study also extends the literature for students with severe symptoms of ASD and ID, an often under-represented population.

\section{Research Questions}

The following central question and two sub-questions guide this study:

Central Question: To what degree does a VSM intervention developed from a functional behavior assessment impact classroom behavior in students with ASD and ID?

Sub Aim 1) What effect will the VSM have on aggressive behavior?

Sub Aim 2) What effect will the VSM have on the replacement behavior? 


\section{CHAPTER THREE}

\section{METHODS}

The purpose of the following study is to test an intervention that combines both VSM and functional assessment as a strategy to promote socially appropriate selfregulation skills and decrease aggressive behavior. The method and intervention procedures will be described below.

\section{Setting of Study}

Participants were recruited from a self-contained school in the Midwestern United States. The school served approximately 172 individuals, ages five to fourteen years, with a variety of moderate and significant special needs as identified by educational diagnosis (Intellectual Disabilities, Emotional Behavior Disorder, Autism Spectrum Disorder, Multiple Needs, Other Health Impairments). The primary form of instruction in the school utilized Applied Behavior Analysis (ABA) principles (e.g., behavior intervention plans, functional assessments, structured environmental supports, and functional communication systems) in addition to school-wide positive behavior supports (SWPBIS).

\section{Criteria for Participant Selection}

The following criteria were used for participation in this study: (a) not currently receiving any form of behavior therapy outside of the school setting; (b) a score on a standardized diagnostic measurement that puts the student in the "severely impacted"

range for ASD or classified as having "severe" ASD (e.g., a score equal to or greater than 37 on the Childhood Autism Rating Scale ${ }^{\mathrm{TM}}-2$ (CARS-2), (Schopler, \& Van Bourgondien, 2010); or a score greater than 75 on the Social Responsiveness Scale ${ }^{\mathrm{TM}}$ 
(SRS) (Constantino, 2005); (c) a score on a standardized diagnostic measurement that puts the student in the category for having an intellectual disability (e.g., a score less than or equal to 70 on the Developmental Profile $\mathrm{TM}_{-} 2$ (DP-2) (Alpern, 2007); (d) an established reinforcement system (e.g., token economy); (e) able to visually attend to a video monitor for up to 1 minute; and (f) a classroom teacher report of levels of aggression that impede the student's ability to participate in the curriculum.

\section{Participants}

Based on teacher reports, two participants emerged as candidates for the intervention given high levels of aggressive behavior across stimulus conditions and inconsistent use of pre-taught replacement skills. The first participant, David (pseudonym), was seven years old at the beginning of the study. According to school records David was not currently receiving any form of behavior therapy outside of the school setting and had a score of 42 on the CARS- 2 which classified him as having a "severe" ASD. He had a score of 42 on the DP-2 which classifies him as having an intellectual disability. He had an IEP in place and an established reinforcement system (e.g., token economy). David enjoyed spending time on the computer, thus was able to attend to a video monitor. Despite educational supports (e.g., a behavior intervention plan) and high levels of reinforcement (e.g., verbal praise, use of preferred items) his teacher reported levels of aggression that impeded his ability to participate in various school-wide activities and the curriculum. According to reports, when David became upset he threw objects, scratched, hit, pulled hair, and/or bit teachers, caregivers and/or other students. His aggressive behavior resulted in the necessity for him to be restrained or placed in a secure observation room until he had calmed down. David's current 
behavior plan hypothesized that his behaviors were an attempt to escape a task, and his replacement behavior was a verbal cue to signify the need for a break.

Participant two, Nate (pseudonym), was twelve years old at the beginning of the study. According to school records he was not currently receiving any form of behavior therapy outside of the school setting and had a score of 76 on the SRS which classified him as having "severe" ASD. He had a score of $<40$ on the DP-2 which classified him as having an intellectual disability. Nate had an IEP in place and an established reinforcement system (e.g., token economy). Nate enjoyed watching videos on the classroom iPad® and was, therefore, able to attend to a video monitor. Despite educational supports (e.g., behavior intervention plan) and high levels of reinforcement (e.g., scheduled breaks from demands, verbal praise, use of preferred items), his teacher reported levels of aggression that impeded his ability to participate in various schoolwide activities and the curriculum. It was reported that Nate mainly scratched and/or pulled hair. When Nate struck a teacher, he began to laugh and the likelihood for aggressive behavior elevated. Staff concluded that Nate enjoyed the struggle of restraint, therefore when he became aggressive he was given personal space (at least 1 to 2 feet). Nate's current behavior plan hypothesized that his behaviors were an attempt to escape a task, and his replacement behavior was to make a request (using picture icons) to signify the need for a break.

Each participant was in a different classroom, thus had different staff. David spent most of his day in an elementary classroom with a lead teacher and a one-on-one paraprofessional. For 30 minutes each day, David went to Music, Art, or Computers, each held in a different location within the school. Additionally, David went to lunch for 
30 minutes in the cafeteria each day. Nate spent the majority of his day in a middle school classroom with a lead teacher and a one-on-one paraprofessional. Nate went to computer class two times per week for 30 minutes. He went to lunch in the cafeteria for 30 minutes each day. Nate received both Music and Art instruction in his classroom setting. Both participants' daily routine consisted of direct instruction, individualized work tasks, small group tasks, and a series of earned breaks from demands.

\section{Participant Preferences and Function of Aggressive Behavior}

Several measures were implemented to determine student preferences and function of aggressive behavior in order to develop the VSM intervention. (See figure 3 for overview.)

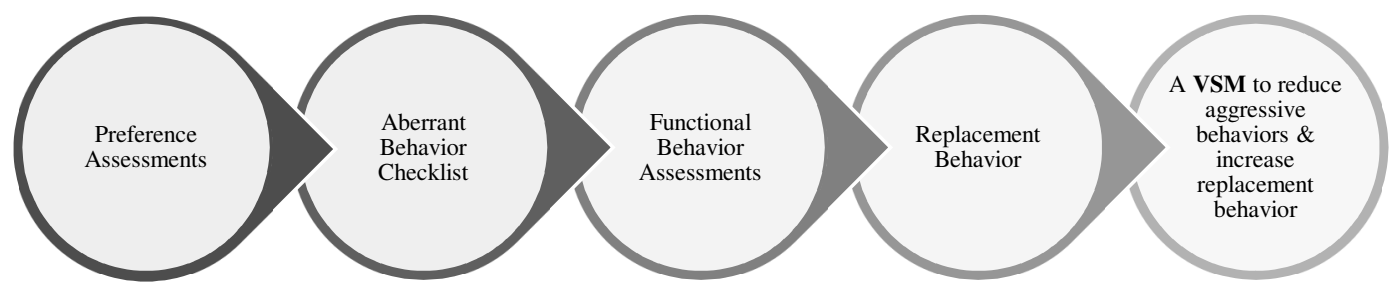

Figure 3. Summary of Measures used to Determine VSM Intervention

Preference Assessments. Each child's caregiver and classroom teacher completed an interest inventory and a questionnaire to determine personal preferences and challenges for the participants. Semi-structured interviews with the classroom teacher (see Appendix A) and the child's caregiver (see Appendix B), were conducted by 
the primary investigator to further assess the student's preferences, strengths, and areas of concern. From the data, it was determined that David enjoyed navigating YouTube on the computer, watching characters from Dinosaur Train, and playing with toys that he brought from home. Nate enjoyed Dora the Explorer, listening to music, and swinging.

Aberrant Behavior Checklist. Students were evaluated using the Aberrant Behavior Checklist (ABC-2; Aman \& Singh, 2017; $\alpha=.65$ to .41 ) to determine the severity of their aggressive behaviors and offer a hypothesis of behavior function. The $\mathrm{ABC}$ is a symptom checklist for assessing problem behaviors of children with developmental disabilities. Scores indicated that David exhibited high rates of maladaptive behaviors as an attempt to seek attention and escape from task demands during instruction. This report aligned with teacher descriptions that David became aggressive when a preferred adult was not speaking to him or when he was presented with a non-preferred task. Scores indicated that Nate exhibited high rates of maladaptive behaviors as an escape from demands and often results in hyperactivity during instruction. This report reinforced the description his teachers gave regarding Nate using aggression to escape task demands and exhibiting interfering self-stimulatory behaviors after he successfully strikes another individual.

Functional Behavior Assessment. A functional assessment of behavior was conducted to ensure that the reinforcing consequence of the aggressive behavior was precisely targeted. Selected participants underwent a functional assessment of behavior by a qualified independent observer (i.e., Board Certified Behavior Analyst [BCBA]). Challenging situations that typically resulted in aggressive behaviors were recorded and analyzed using both direct and indirect methods. For this study two data sources, 
Questions About Behavioral Function (QABF; Matson \& Vollmer, 1995; $\alpha=.88$ to .79), Antecedent-Behavior-Consequence (ABC; Bijour, Peterson, \& Ault, 1968) were utilized by the BCBA certified observer.

$\boldsymbol{Q A B F}$. The QABF is a measure designed for the functional assessment of behavior problems in persons with developmental disabilities. The instrument yields five categories reflecting the behavioral functions of Attention, Escape, Physical, Tangible, and Nonsocial. The BCBA certified observer gathered data from two teachers per participant (e.g., David's teacher and para-professional and Nate's teacher and school behavior specialist). Results from the QABF indicated that David's behaviors were equally split between a desire for attention and an effort to escape a task. Results from the QABF indicate that Nate's aggressive behaviors were the result of a desire to escape a task demand.

ABC Observations. Antecedent, behavior, consequence (ABC) data was collected by the BCBA certified observer and the primary investigator during times that were reportedly "difficult" for each student. David displayed aggression when asked to work at his desk, participate in lunchroom routines, and participate in structured activities outside the classroom (e.g., Music class). David also displayed aggressive behaviors during non-structured activities when a preferred adult was playing with another student in the classroom. These behaviors served to gain attention from a preferred adult. David also displayed aggressive behavior when he was asked to transition from a preferred task to a non-preferred task.

$\mathrm{ABC}$ data reflected that Nate was initially compliant when asked to join a structured activity (e.g., he would willingly walk to the designated location). However, 
once he was prompted to engage, he would not comply. Aggressive behaviors were observed across several conditions including center time instruction (e.g., task boxes located in the back of the room), instruction at his desk, and during small group instruction at a large table. When Nate's teachers prompted him to engage in the task, he displayed aggression, began to laugh, and engaged in interfering self-stimulatory behaviors (e.g., slapping his chest or head with an open palm, stomping his feet, or hitting a hard surface with a closed fist).

Hypothesis Statement. Based on the data collected from the functional assessment \& QABF, it was hypothesized that David's aggressive behavior served two functions (attention seeking and escape or avoidance) based on different environmental stimuli. David's teacher reported that the escape-maintained behaviors caused greatest loss of instructional time in various settings, therefore it was determined that the intervention would focus on replacing aggression with a replacement behavior across three problematic stimulus conditions: (1) work at his desk, (2) in the lunch room, and (3) in the Music classroom. Nate's aggressive behavior served to escape or delay nonpreferred tasks. The behaviors occurred most frequently in his classroom during three different stimulus conditions (1) small group activities, (2) center-time instruction, and (3) individual work at his desk.

\section{Research Design}

For this study a multiple baseline design across stimulus conditions with intersubject replication was used (Gast \& Ledford, 2014; Horner, et al., 2005). A stimulus condition was defined as an instructional arrangement (e.g., one-on-one instruction, group instruction, or a particular classroom setting; Gast \& Ledford, 2014). Three unique 
stimulus conditions were identified per participant based upon data obtained from preference and functional assessment measurements. In a multiple baseline model, the participant serves as his own control and his/her performance prior to the intervention was compared to the performances during and after the intervention (Gast \& Ledford, 2014).

An inter-subject replication refers to "repeating the same effect with different participants" (p. 109, Gast \& Ledford, 2014). To conduct an inter-subject replication the following criteria were adhered to per suggestion from Barlow and Hersen (1984): (1) the investigator, setting, materials, and instructional arrangements should be consistent across participants; (2) the dependent variable and measurements should be similar across participants; (3) participants should have similar abilities related to inclusion criteria; and (4) the independent variable should be the same. The primary investigator was the main source of data collection for both participants. The participants ranged in age from 7 to 12 years, and had similar target behaviors and instructional arrangements. The dependent variables and measurements were consistent across both studies.

\section{Dependent Variables}

Aggression. The first dependent variable was aggressive behavior and was the same across participants. For the purpose of this study, "aggressive behavior" was operationally defined as any instances of the following: physical contact that results in harming oneself or another individual (e.g., biting, hitting, kicking, scratching, pulling hair, or using items as weapons). Aggression was selected as a dependent variable because data reported high rates, thus the current study aimed to decrease aggressive behaviors via VSM. 
Replacement behavior. The replacement behavior was operationally defined as any time the student requested a break from the demand and engaged in a "break task." When the participant requested a break, task demands were removed and the students' were presented with a break task designed to help them cope with stress related to the original non-preferred task demand. The break and break task strategies were selected as dependent variables because the data concluded that both participants experienced performance deficits, thus the current study aimed to increase the use of pre-taught replacement behaviors via VSM.

David's break task was a pre-taught "mindfulness" strategy (i.e., counting to 10 , 10 deep breaths, 10 hand squeezes, 10 cheek squeezes). Once the break task was complete, the original task was presented again. This sequence of events (request a break and engage in a break task) mirrored his current behavior intervention plan that had been minimally effective. During baseline data collection, it was observed that David did not independently ask for a break when he was frustrated, but he would often respond when given a cue (e.g., a teacher holds up one finger and begins to count). On several occasions, after being prompted, David engaged in the break task but would resort to aggression when he was asked to complete the original task demand.

After a break from a demand was initiated by Nate (via pointing to an icon or handing a teacher an icon), he was presented with a break task. Nate's break task was a pre-taught strategy where he selected an item that provided sensory input (e.g., a ball to squeeze, exercise rubber bands to pull with his hands or feet, or items to chew). Once he began to engage with the item, the original task was presented again. This sequence of events (request a break and engage in a break task) mirrored his current behavior 
intervention plan that had been minimally effective. During baseline data, it was observed that Nate occasionally engaged in the break task, but often disregarded it (e.g., dropped the tangible item on the floor) in place of using aggressive behavior.

\section{Independent Variable}

The independent variable for this study was the VSM. The fundamental aspects of the independent variable (the VSM) was consistent with previous VSM studies: (1) self-as-model; and (2) features the individual independently performing the replacement behavior under typically stressful conditions (e.g., when given a non-preferred task demand).

VSM Features. The VSMs were created in accordance to suggestions by previous research: (1) no more than 3 minutes in length (Dowrick, 1983); (2) viewed at least one time per day (Buggey, 2009; Dowrick, 1999, 2012); (3) all adult and peer supports edited out (Buggey, 2009; Dowrick, 1999, 2012; Gelbar, et al., 2012); (4) demonstrates a positive self-image (Bellini \& Akullian, 2007; Buggey, 2009; Dowrick, 1999, 2012); and (5) clearly defined outcomes of the target behavior (Bandura, 1977, 1989; Bellini \& McConnell, 2010; Buggey, 2009; Dowrick, 1999; 2012). The videos placed a strong emphasis on the student successfully demonstrating socially appropriate behavior amidst conditions that were typical of triggering an aggressive episode.

Video Development. Using the data collected via the functional assessment and preference measures, a video was developed that depicted the learner demonstrating the replacement behavior and receiving a desirable consequence. As a means of engaging the learner and maintaining interest in the video, a background song or sound effect unique to each participant was played, on low volume, for varying lengths based upon 
student needs. The inclusion of visual effects and/or images of preferred characters was individualized across videos.

To create the videos the footage was captured (using an iPhone 6 plus) and edited by the primary investigator to create a systematic, engaging, movie using Windows Movie Maker@ and Screencast-O-matic $@$ software. Prior to filming, a storyboard was created that depicts the sequence of events that the video aims to capture (see Appendix C). Students were recorded during stimulus conditions that were typically challenging for them (e.g., lunch room, instructional time), during instances that they prefer (e.g., free play), and during staff attempts to redirect aggressive behavior (e.g., attempts at using a socially appropriate replacement strategy). This video footage was used to create the final product that the participant viewed during the intervention (see Appendix D).

\section{Intervention Procedures}

Experimental procedures used in this study are described below and include information on data collection procedures, intervention phases, treatment fidelity, observer training, inter-observer agreement, and social validity.

Data Collection. A partial interval recording system was used to collect data on the two dependent variables (aggression and replacement behavior) for a total of 25 nonsequential days. The partial intervals were 10 seconds in length. In partial interval recording, the observer marks down whether a behavior occurs any time during the designated period of time by placing a "+" for occurrence and a " 0 ” for non-occurrence. An observational period lasting 30 minutes occurred for each stimulus condition per participant. This allowed for a total of 180 intervals per stimulus condition for a total of 540 intervals of data collection per participant each day (see Appendix E). Data was 
collected by the primary researcher during every interval, and an independent observer simultaneously recorded student behavior for $40 \%$ of the total number of intervals.

Baseline. Baseline conditions consisted of typical classroom interventions. The baseline condition continued until a pattern in the data for the dependent variables was apparent (e.g., 3 to 5 data points) (Horner, et al., 2005; WWC, 2014). Once a baseline pattern in the data was established, the intervention was presented in the first condition, while baseline procedures continued in the second and third conditions. When a therapeutic pattern of data was established in the first condition, the intervention was then presented in the second condition, while baseline procedures continued in the third condition. When a pattern in the second condition occurred, the third condition began the intervention phase (Gast \& Ledford, 2014).

Stimulus Condition 1 (SC1). Following baseline, the VSM depicting the student engaging in the replacement behavior during SC1 was shown one time at the beginning of the school day. For David, the VSM for this condition depicted him using his replacement behavior at his desk in his classroom. Nate's VSM for this condition depicted him using his replacement behavior in a small group located at a large table in his classroom.

Stimulus Condition 2 (SC2). Once a therapeutic pattern in the data was established in SC1 (e.g., three to five data points) the VSM that depicted the student engaging in the replacement behavior during both SC1 and SC2 was then shown at the beginning of the school day. For David, SC2 added a depiction of him using his replacement behavior in the lunchroom. For Nate, SC2 added footage of him using his 
replacement behavior during "center time" (located in a semi-private desk in the back of the classroom).

Stimulus Condition 3 (SC3). Once a therapeutic pattern was established in SC2, the VSM that depicted the student engaging in the replacement behavior during SC1, SC2, and SC3 was shown at the beginning of the school day. For David, SC3 added a depiction of him using his replacement behavior in the Music classroom. For Nate, SC3 added footage of him using his replacement behavior during instruction while he was seated at his own desk inside the classroom.

Maintenance. For David, maintenance data was collected on days 5, 9, 17, 20, and 24 post-intervention. For Nate, maintenance data was collected on days 3, 6, 10, 18, and 21 post-intervention. During the maintenance phase, the teacher and behavior analyst were instructed to cease playing the videos for the student each morning, but were asked to honor any request independently made by the student to view the VSM (e.g., if the student sought adult assistance to watch the VSM).

\section{Treatment Fidelity}

A treatment fidelity was conducted to ensure that classroom staff was implementing the expectations of each stimulus condition consistently. For example, in stimulus condition one for David, the observer reported if the following criteria was adhered to; (1) was the student required to remain seated in a chair; (2) was he expected to follow instructions; (3) were task demands given; and (4) was the VSM played for the participant one time each morning? The primary and second observer completed a checklist immediately following each stimulus condition (see Appendix F and G)

\section{Inter-Observer Training and Agreement}


Prior to collecting data, independent observers participated in a training session using videos that consisted of samples of both aggressive behavior and replacement behavior per participant. During training, inter-rater scores were calculated and the training(s) continued until 100\% agreement was achieved (e.g., the data collectors came to an agreement that an aggressive or socially appropriate behavior did or did not occur). To practice interval synchronicity, observers were trained to listen to a private audio recording (using Smartphone technology) that indicated the beginning and end of each interval intended for observation.

Data was collected by the primary researcher $100 \%$ of intervals. IOA data was collected on $40 \%$ of the total number of intervals by a trained independent observer (e.g., doctoral students in the college of Special Education). This percentage is sufficient according to standards in the literature (Carroll et al., 2007; Horner, et al., 2005; Kratochwill, et al., 2010; WWC, 2014). The IOA was dispersed among baseline, intervention, and maintenance phases. The total number of agreements divided by the total number of agreements and disagreements yielded the percentage of inter-observer agreement. Inter-observer agreement for all collected data was at 99\%. A Kappa statistic (Cohen, 1960) was established by dividing the total agreement by the chance agreement. Cohen's Kappa was calculated at 0.98 which indicates almost perfect agreement.

\section{Social Validity}

Social validity was measured via a researcher-developed questionnaire given to two classroom teachers and two paraprofessionals familiar with the participants. The interviews allowed the primary investigator to ensure that the VSM intervention is 
minimally invasive to classroom instruction and helped determine the feasibility of dissemination. The social validity questionnaire consisted of the following questions:

(1) Are you able to deliver the intervention with fidelity? Is the video being viewed regularly? Is the replacement... being used?

(2) Do you have the appropriate resources to deliver the intervention (e.g., electronic devices for viewing, tangible reinforcements, communication systems, visual supports)?

(3) Do you feel that the self-regulation strategy has social importance in the school?

(4) Do you believe the intervention is having an impact on the student?

(5) Would you consider using the intervention after the study is complete?

(6) Do you are any of your staff require additional instruction or support regarding the intervention procedures? 


\section{CHAPTER FOUR}

\section{RESULTS}

In the following chapter the results will be reported via three analysis procedures: (1) visual analysis of the dependent variables, (2) mean performance, and (3) the percentage of data points exceeding the median (PEM) across the three stimulus conditions for each student (David and Nate). The chapter will conclude with a summary of the teacher responses related to the social validity of the intervention.

\section{Visual Analysis of Dependent Variables}

A visual analysis of the data was performed to determine whether evidence of a functional relationship between an independent variable and an outcome variable exists and the strength or magnitude of that relation (Gast \& Ledford, 2012; Kratochwill, et al., 2012; What Works Clearinghouse, 2002 [WWC]).

\section{David.}

Baseline. Figure 4 shows instances of baseline aggression (indicated in black with closed circles) for David. During stimulus condition 1 (SC1), baseline lasted four sessions. Stimulus condition 2 (SC2), baseline lasted nine sessions and baseline for stimulus condition 3 (SC3) lasted 13 sessions. In the SC3 baseline condition, data point 9 is missing. This is due to music class not being conducted that day per teacher decision. For all three stimulus conditions, David typically displayed high levels of aggression (range 1 to 45 instances). When lower rates of aggression were documented (data points 1, 6, and 11) intervening "environmental" factors were likely responsible. For example, during SC3 anecdotal notes from data points 6 and 11 indicate that David was given extra choice time (up to 11 minutes) beyond what he was typically given (2-3 mins) during 
data collection. For data point 1 in SC3, David was allowed to sit on a teacher's lap during classroom instruction (something he preferred) and as a result he was not made to complete tasks independently.

Figure 4 shows instances of baseline replacement behavior (indicated in gray with open squares). Overall, low rates of replacement behavior were apparent across all stimulus conditions for David (range 0 to 18 instances). Overlapping data points can be explained by interfering environmental factors. For example, in SC3 two of the overlapping data points, data points 6 and 7, can be explained by shortened work sessions, longer breaks from demands, and reduced task difficulty due to the teacher being absent that day (e.g., a work session that typically lasts 30-minues but only lasted 8-minutes on day 6 and 7-minutes on day 7). Another anomaly occurred on data point 13. For part of the observation during this data point, David's aggressive behavior became so intense that staff placed a "secure observation room" (e.g., a padded room with the ability to close and lock the door; students are monitored through a window and video monitoring). On this day, it was observed that David was improperly using the replacement behavior (e.g., going through the motions of the break task in an effort to prompt the teacher to open the door). This was supported by observations of David using the opportunity of an open door to immediately resort back to aggression. The high rate of replacement behavior for this data point is due to the extra time the teachers had to prompt him through the strategy and the instances that David executed the strategy, but had not actually regained control of his anger.

Intervention. As demonstrated by figure 4, SC1 intervention lasted 16 sessions, (beginning on data point 5). For SC2 intervention conditions lasted 11 sessions 
(beginning on data point 10) and SC3 intervention lasted seven sessions (beginning on data point 14). All three stimulus conditions demonstrate a decreasing pattern in the level of aggression that remained stable after the intervention was introduced. Figure 4 illustrates that for SC1 and SC2 the change in the level of aggression occurred immediately following the change in phase. For SC3, evidence of change is apparent on the second day of intervention onward. The change in variability from baseline to intervention conditions suggest that the intervention had the desired effect for reducing aggressive behavior. Interestingly, the level of replacement behavior is either higher than or equal to the rate of aggression across all stimulus conditions, with the exception of data point 11 in SC2.

Maintenance. For aggression, the maintenance data for SC1, SC2, and SC3 consisted of 5 data points up to 24 days post-intervention. The level of performance in the maintenance condition is similar to the intervention condition across SC1, SC2, and SC3, according to figure 4. All three stimulus conditions demonstrate a continuation of low rates of aggression as evidenced during the intervention condition. Similar to the intervention condition the rate of pro-social behavior was higher than or equal to the rate of aggression in all data points. 


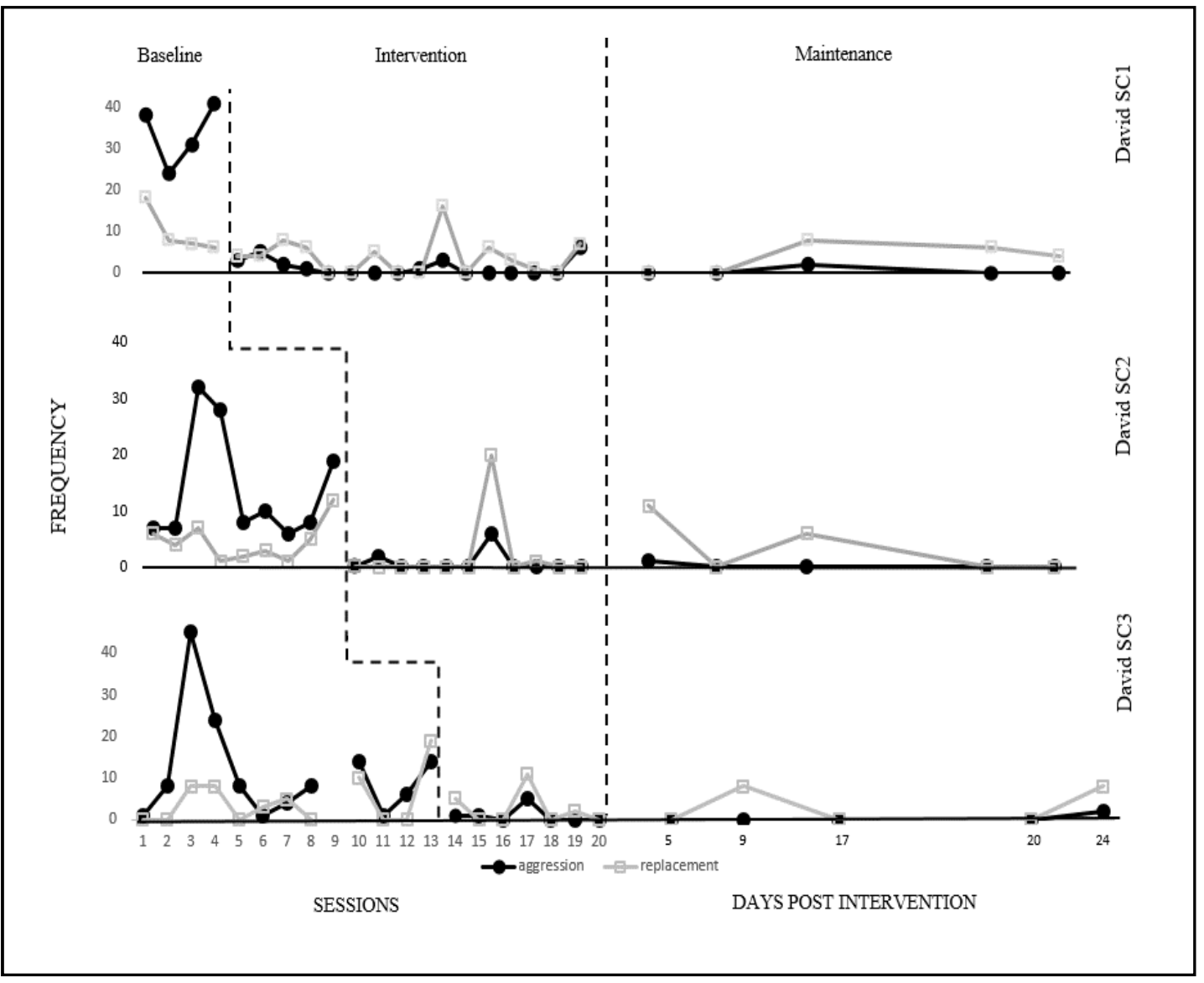

Figure 4: Instances of the Dependent Variables Across Stimulus Conditions for David 
Nate.

Baseline. Figure 5 shows instances of aggression during baseline conditions (indicated in black with closed circles) for Nate. For SC1, baseline lasted five sessions. For SC2, baseline lasted 10 sessions and for SC3 baseline lasted 15 sessions. For all 3 stimulus conditions, Nate displayed high levels of aggression (range 1 to 55 instances). Some of the variability and the anomalies in the data can be accounted for by the interfering environmental factors. For instance, in figure 5, data point 10 was only recorded one time (during SC1) because Nate left for a doctor's appointment and did not return until the next day. In SC3, data points 13 and 15 are missing because small group instruction was not conducted that day due to teacher decision.

Figure 5 shows instances of baseline replacement behavior for Nate (indicated in gray with open squares). Overall, low rates of prosocial behavior were apparent across stimulus conditions for Nate. Some of the variability and the anomalies can be accounted for by the environmental factors stated above. For replacement behavior, a low level of performance occurred during SC1 and is supported by a decreasing trend. During SC2 and SC3 there are lower levels of replacement behavior compared to levels of aggression.

Intervention. Figure 5 also shows instances of aggression (indicated in black with closed circles) during intervention conditions for Nate. As demonstrated by figure 5, the SC1 intervention lasted 15 sessions (beginning on data point 6), SC2 intervention lasted 10 sessions (beginning at data point 11), and SC3 intervention condition lasted five sessions (beginning on data point 16). All three stimulus conditions demonstrate a pattern of decreased level of aggression after the intervention is introduced. Figure 5 illustrates that the change in levels of aggression occurred immediately following the 
change in phase for SC1 and SC2. For SC3, evidence of change is apparent beginning on the second day of intervention. The change in variability from baseline to intervention conditions suggest that the intervention may have resulted in reducing levels of aggressive behavior.

For replacement behavior data (indicated in gray with open squares) the length of each condition mirrored that in the aggression data stated above. For replacement behavior, the outcome levels were higher during the intervention condition compared to baseline. High variability is apparent across all stimulus conditions however, the rate of replacement behavior was higher than the rate of aggression in all but six points when they mirrored that rate of aggression at zero.

Maintenance. For aggression, the maintenance data for SC1, SC2, and SC3 consisted of five data points lasting up to 21 days post intervention. The level of performance in the maintenance condition is similar to the intervention condition across SC1, SC2, and SC3, according to figure 5. Similar to the intervention condition, the rate of replacement behavior was higher than the rate of aggression in all but four data points when the rate of replacement behavior and aggression was at zero. 


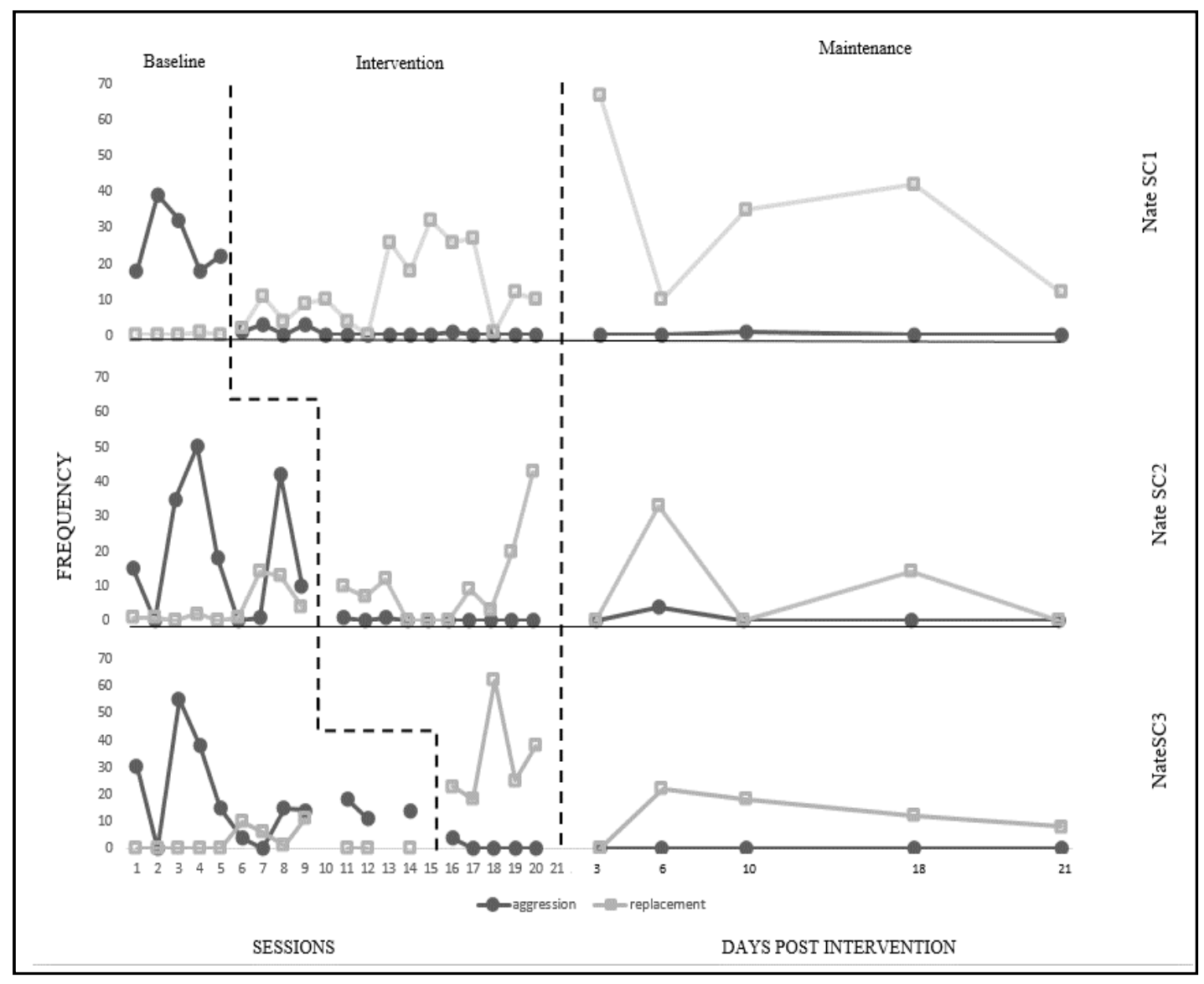

Figure 5: Instances of the Dependent Variables Across Stimulus Conditions for Nate 


\section{Mean Performance for Dependent Variables across Stimulus Conditions}

David. Table 2 displays the average occurrence of the dependent variables (aggressive and replacement behavior) across stimulus conditions for David. For SC1 aggressive incidents occurred at a rate of $33.5 \%$ of intervals during baseline, decreased to $1.31 \%$ during intervention and further decreased to $0.4 \%$ during maintenance. For SC2, aggressive incidents occurred at a rate of $13.88 \%$ during baseline, decreased to $0.72 \%$ during intervention, and further decreased to $0.2 \%$ during maintenance. For SC3, aggressive incidents occurred at a rate of $11 \%$ during baseline, decreased to $1 \%$ during intervention, and further decreased to $0.4 \%$ during maintenance.

The mean performance of David's replacement behavior was also calculated. For SC1 the replacement behavior occurred at a rate of $9.75 \%$ of intervals during baseline, decreased to $3.75 \%$ during intervention, and $3.6 \%$ during maintenance. For SC2, the replacement behavior occurred at a rate of $4.5 \%$ during baseline, decreased to $1.9 \%$ during intervention, and increased to 3.4\% during maintenance. During SC3's baseline, the replacement behavior occurred at a rate of $4.46 \%$, decreased to $2.16 \%$ during intervention, and increased to $3.2 \%$ during maintenance. 
Table 1

David's Mean Occurrence of Dependent Variables Across Stimulus Conditions

\begin{tabular}{|c|c|c|c|c|c|c|}
\hline & \multicolumn{3}{|c|}{ Aggression } & \multicolumn{3}{|c|}{ Replacement behavior } \\
\hline & Baseline & Intervention & Maintenance & Baseline & Intervention & Maintenance \\
\hline $\mathrm{SC} 1$ & $33.50 \%$ & $1.31 \%$ & $0.4 \%$ & $9.75 \%$ & $3.75 \%$ & $3.6 \%$ \\
\hline $\mathrm{SC} 2$ & $13.88 \%$ & $0.72 \%$ & $0.2 \%$ & $4.50 \%$ & $1.90 \%$ & $3.4 \%$ \\
\hline $\mathrm{SC} 3$ & $11.00 \%$ & $1.00 \%$ & $0.4 \%$ & $4.46 \%$ & $2.16 \%$ & $3.2 \%$ \\
\hline
\end{tabular}

Note. $\mathrm{SC} 1=$ Stimulus condition 1, SC2= Stimulus condition 2, SC3= Stimulus condition 3

Nate. Table 3 displays the average occurrence of dependent variables (aggressive and replacement behavior) across stimulus conditions for Nate. For SC1 aggressive behaviors occurred at a rate of $25.8 \%$ of intervals during baseline; decreased to $0.53 \%$ during intervention, and $0.2 \%$ during maintenance. For SC2, aggressive behaviors occurred at a rate of $19 \%$ during baseline; decreased to $0.2 \%$ during intervention, and $0.8 \%$ during maintenance. For SC3 aggressive behavior occurred at a rate of $17.83 \%$ during baseline, decreased to $0.8 \%$ during intervention, and $0 \%$ during maintenance.

The mean performance of Nate's replacement behavior was also calculated. For SC1 Nate's replacement behavior occurred at a rate of $0.2 \%$ of intervals during baseline, increased to $12.8 \%$ during intervention, and further increased to $33.2 \%$ during maintenance. For SC2, replacement behavior occurred at a rate of $4 \%$, increased to $10.06 \%$ during intervention; and decreased to $9.4 \%$ maintenance. For SC3, the replacement behavior occurred at a rate of $2.3 \%$ during baseline, increased to $33.2 \%$ during intervention, and decreased to $12 \%$ during maintenance. 
Table 2

Nate's Mean Occurrence of Dependent Variables Across Stimulus Conditions

\begin{tabular}{|c|c|c|c|c|c|c|}
\hline & \multicolumn{3}{|c|}{ Aggression } & \multicolumn{3}{|c|}{ Replacement behavior } \\
\hline & Baseline & Intervention & Maintenance & Baseline & Intervention & Maintenance \\
\hline $\mathrm{SC} 1$ & $25.80 \%$ & $0.53 \%$ & $0.2 \%$ & $0.2 \%$ & $12.80 \%$ & $33.2 \%$ \\
\hline $\mathrm{SC} 2$ & $19.00 \%$ & $0.20 \%$ & $0.8 \%$ & $4.0 \%$ & $10.06 \%$ & $9.4 \%$ \\
\hline SC3 & $17.83 \%$ & $0.80 \%$ & $0.0 \%$ & $2.3 \%$ & $33.20 \%$ & $12.0 \%$ \\
\hline
\end{tabular}

Note. $\mathrm{SC} 1=$ Stimulus condition 1, SC2 = Stimulus condition 2, SC3= Stimulus condition 3

\section{Effect Size of the Intervention across Stimulus Conditions}

The percentage of data points exceeding the median (PEM) (Ma, 2006) was used to determine the effect size of the intervention. PEM was selected because the aggressive behavior was highly variant for these participants and a single ceiling or floor level data point would not be indicative of actual behavioral performance (Ma, 2006; Vannest, et al., 2015). In this type of analysis, the median of data points during the baseline phase are calculated to determine the effect size of the intervention. The PEM involves calculating the number of data points showing improvement from the baseline median score divided by the total number of data points in the intervention conditions (Ma, 2006; Vannest, et al., 2015). The number of data points above or below the median line in the intervention phase is then divided by the total number of data points.

In the present study, two dependent variables were calculated (aggression and replacement behavior). The undesired behavior (aggression) was expected to decrease after the intervention was introduced, therefore the PEM calculations reflect the percentage of data points below the median level calculated in baseline. The replacement 
behavior was expected to increase after the intervention is introduced, therefore the PEM calculations reflect the percentage of data points above the median level calculated in baseline. The following guidelines were used to explain the effects using PEM: 90-100\% is a highly effective treatment, $70-90 \%$ is a moderately effective treatment, $50-70 \%$ is a minimally effective treatment, and less than $50 \%$ is not effective (Scruggs, Mastropieri, Cook, \& Escobar, 1986).

David. Table 4 displays the PEM calculations of the dependent variables (aggressive and replacement behavior) across stimulus conditions for David. During David's SC1 baseline, the median number of aggression instances was calculated at 34.5. During both the intervention and maintenance phases, $100 \%$ of the data points were below the median rate of aggression, suggesting that the intervention was highly effective. David's SC2 baseline PEM for aggression was calculated at 8. During both the intervention and maintenance phases, $100 \%$ of the data points were below the median rate of aggression, suggesting that the intervention was highly effective. David's SC3 baseline PEM for aggression was calculated at 8 . During both the intervention and maintenance phases, $100 \%$ of the data points were below the median rate of aggression, suggesting that the intervention was highly effective.

The median rate of replacement behavior was calculated to be 7.5 at baseline. During SC1 intervention in SC1, $18.75 \%$ exceeded the median; maintenance for this condition was calculated to be $20 \%$. Both of the PEM calculations suggest that the intervention had no effect on replacement behavior during SC1. David's SC2 baseline PEM for replacement behavior was calculated at 4. During SC2 intervention $18 \%$ exceeded the median; maintenance for this condition was calculated at $40 \%$. Both of the 
PEM calculations suggest that the intervention had no effect on replacement behavior during SC2. David's SC3 baseline PEM for replacement behavior was calculated at 3. During both intervention and maintenance on SC3, $16 \%$ exceeded the median. Both of the PEM calculations suggest that the intervention had no effect on replacement behavior during SC3.

Table 3

David's PEM Calculations

\begin{tabular}{|c|c|c|c|c|}
\hline & \multicolumn{2}{|c|}{ Aggression } & \multicolumn{2}{|c|}{ Replacement behavior } \\
\hline & Intervention & Maintenance & Intervention & Maintenance \\
\hline $\mathrm{SC} 1$ & $100 \%$ & $100 \%$ & $18.75 \%$ & $20 \%$ \\
\hline $\mathrm{SC} 2$ & $100 \%$ & $100 \%$ & $11.00 \%$ & $40 \%$ \\
\hline SC3 & $100 \%$ & $100 \%$ & $16.00 \%$ & $20 \%$ \\
\hline
\end{tabular}

Note. $\mathrm{SC} 1=$ Stimulus condition $1, \mathrm{SC} 2=$ Stimulus condition 2, SC3= Stimulus condition 3

Nate. Table 5 displays the PEM calculations of the dependent variables (aggressive and replacement behavior) across stimulus conditions for Nate. During Nate's SC1 baseline, the median number of aggression instances was calculated at 25.8. During both the intervention and maintenance phases, $100 \%$ of data points were below the median rate of aggression, suggesting that the intervention was highly effective. During Nate's SC2 baseline, the median number of aggression instances was calculated at 19. During both the intervention and maintenance phases, $100 \%$ of data points were below the median rate of aggression, suggesting that the intervention was highly effective. During Nate's SC3 baseline, the median number of aggression instances was 
calculated at 14 . During both the intervention and maintenance phases, $100 \%$ of data points were below the median rate of aggression, suggesting that the intervention was highly effective.

During SC1, the median rate of replacement behavior was calculated to be zero at baseline. During the intervention, $93 \%$ of data points exceeded the median rate and $100 \%$ exceeded the median during maintenance, both suggesting a high effect. During $\mathrm{SC} 2$, the median rate of replacement behavior was calculated to be 7 at baseline. During the intervention, $60 \%$ of data points exceeded the median rate suggesting a mild intervention effect whereas $40 \%$ exceeded the median during maintenance suggesting no effect. During SC3, the median rate of replacement behavior was calculated to be zero at SC3 baseline. During the intervention, $100 \%$ of data points exceeded the median rate suggesting a highly effect. During the maintenance condition of SC3, 80\% of data points exceeded the median rate also suggesting a high intervention effect. 
Table 4

Nate's PEM calculations

\begin{tabular}{|c|c|c|c|c|}
\hline & \multicolumn{2}{|c|}{ Aggression } & \multicolumn{2}{|c|}{ Replacement behavior } \\
\hline & Intervention & Maintenance & Intervention & Maintenance \\
\hline $\mathrm{SC} 1$ & $100 \%$ & $100 \%$ & $93 \%$ & $100 \%$ \\
\hline $\mathrm{SC} 2$ & $100 \%$ & $100 \%$ & $60 \%$ & $40 \%$ \\
\hline $\mathrm{SC} 3$ & $100 \%$ & $100 \%$ & $100 \%$ & $80 \%$ \\
\hline
\end{tabular}

Note. $\mathrm{SC} 1=$ Stimulus condition 1, SC2 = Stimulus condition 2, SC3= Stimulus condition 3 Social Validity and Treatment Fidelity

For the first participant, (David) data was collected from the special education teacher and the student's paraprofessional. When asked about intervention fidelity and if the classroom staff needed support implementing the intervention, both individuals reported that the video was easily accessed from the classroom computer (where it was saved to the desktop by the primary investigator) and the video itself explained how to support David's replacement behavior. For instance, the teacher said, "If anyone had questions about what he [David] was doing I just told them to watch the video.” In regard to social importance, both responders suggest that the replacement behavior was highly valued by the school community. The paraprofessional stated, "Other staff was like whoa, what he is doing in the cafeteria?" She continued by saying, "They kept complimenting me on his behavior and I was like, it's not me it's the video!' When asked about the impact the video had on the student, the teacher reported that she had noted a huge difference in his behaviors and that it is "exciting" to have David participate 
in the curriculum. The paraprofessional reported that David, "loves seeing himself on video." She noted that he often laughed when he saw himself and often played the video in reverse in order to watch it repeatedly. Both responders agreed that they would like to continue some form of VSM after the study was complete.

For the second participant, Nate, data was collected from the special education teacher. When asked about intervention fidelity, she indicated that it was easy to implement because it was on an $\mathrm{iPad} \AA$ and the self-regulation skill was in his communication binder. Similar to David's teacher, she also commented that if staff had any questions about the intervention she directed them to watch Nate's VSM. When asked about the social importance, Nate's teacher stated that, "he needs to learn to participate in groups and we finally found something that works." When asked if the VSM had an impact on the student, she stated that, "This is great! He is able to meet his sensory needs and participate in activities. We used to have to remove him from class." To the same question she also stated that, "He selected a strategy and I didn't even realize he was using it during my lesson!" When asked if she would consider using VSM after the study was completed, she said, "Yes! I need one for all my students!"

Finally, when asked if they would consider using the intervention after the study is complete Nate's teacher said, “The technology seems hard to use and I don't think I could create a VSM on my own." She then remarked, "Can you make videos for all my students?" To the same question, David's teacher responded, "I would love to use the intervention if you could make me more videos!" Further work should provide instructions to teachers on how to utilize technology in order to create VSM interventions for students with ASD. 


\section{CHAPTER 5 DISCUSSION}

The current study used multiple baseline design across stimulus conditions with inter-subject replication to explore the following central question: To what degree does a VSM intervention developed from a functional behavior assessment impact classroom behavior in students with ASD and ID? Two sub-questions also guided this research: (1) What effect will the VSM have on selected aggressive behavior and (2) What effect will the VSM have on selected replacement behavior? To answer these questions, two students with ASD and ID who displayed high levels of aggressive behavior across various stimulus conditions and rarely utilized pre-taught replacement skills were identified to participate in the study. Importantly, according to reports, traditional ABA strategies had been ineffective for both participants. The findings from this study are discussed in connection to the sub-questions guiding this research study.

VSM Impact on Aggressive Behavior. The results of the study provide strong support for the effectiveness for the VSM intervention developed from a functional behavior assessment for reducing aggressive behavior of students with ASD and ID. Both visual analysis and effect data demonstrated a large decrease in aggressive behavior across all stimulus conditions for both participants. For David, aggressive behaviors ranged from 11-33.5\% during baseline and ranged from 0-1\% during intervention. For Nate, aggressive behaviors ranged from 17.83-25.8\% during baseline and remained at $0 \%$ during intervention. Visual analysis indicated that the behavior change occurred very rapidly after the onset of intervention and that this pattern was present for the duration of the intervention phase. Both participants maintained lowered levels of aggression after the removal of the intervention. These results begin to address the limited research of 
identifying an evidence-based intervention specifically designed to treat aggressive behaviors for students with ASD and ID (Matson et al., 2008, Matson \& Shoemaker, 2009; O’Brien \& Pearson, 2004; Storch et al., 2012).

Furthermore, this study demonstrates that a functional behavior assessment can be embedded into VSM development to ensure that the correct environmental consequence is being altered in the video. The addition of the functional behavior assessment to the VSM merged two important theoretical constructs for managing behavior which allows for multiple perspectives of analysis that could improve teaching and learning practices. As an illustration, functional behavior assessments, derived from behaviorism, is a scientifically valid method used to reveal the external conditions that contribute to behavioral maintenance (Iwata, et al., 2000), while VSM draws on the union of internal and external consequences to modify behavior (Creer \& Miklich, 1970; Dowrick, 1999, 2012; Gelbar et al., 2012). Together, this joint perspective allows for aggressive behaviors to be functionally identified and measured (Baer, Wolf, \& Risley, 1968; Iwata, et al., 2000), and uses both environmental variables and internal psychological processes (modeling and self-efficacy) to improve self-regulated behavior (Bandura, 1965, 1975; Dowrick, 1999, 2012; Gelbar et al., 2012; Hitchcock, Dowrick, \& Prater, 2003). Consequently, this approach could be particularly advantageous for students with persistent aggressive behavior who do not respond to typical behavior modification strategies (Gelbar et al., 2012). For instance, in both studies the participants had been taught a replacement behavior using ABA strategies however, these strategies where demonstrated inconsistently as high rates of aggressive behavior continued. When the VSM was introduced, the replacement behavior became effective as demonstrated by 
dramatic decreases in aggression. This study provides evidence, that the VSM improved a performance deficit in both individuals.

Equally important, the findings in this study are consistent with previous VSM research which describes the intervention effects occurring immediately and maintaining over time (Bellini \& Akullian, 2007; Buggey, 2005; Dowrick 1999, 2012; Gelbar et al., 2012, Hitchcock, Dowrick, \& Prater, 2003; Schreibman et al., 2000). For both participants, decreases in aggressive behavior were immediate following intervention across all stimulus conditions. Immediate effects can make this intervention cost and time efficient for teachers. Furthermore, the effects of the intervention lasted up to 24 days for David and up to 21 days for Nate. The maintenance of effects over time ensures that skills do not deteriorate at least for a month following intervention. These types of outcomes are exactly what one would hope for in a school-based intervention for aggressive behavior.

VSM Impact on Replacement Behavior. The results of the current study provide moderate support provide for the effectiveness of the VSM and functional behavior assessment intervention at increasing replacement behaviors of students with ASD and ID. For Nate, there was a strong effect size related to the VSM for replacement behavior, however for David, the effect size calculations suggest that the VSM had no effect on the replacement behavior. David's visual analysis suggest some effectiveness due to changes in the response patterns between baseline and interventions conditions. For instance, David's mean level of replacement behavior was lower than the mean level aggression during baseline (baseline replacement behavior means 4.46-9.75\% vs. baseline aggression means 11-33.5\%) and was higher level than the mean level of 
aggression during the intervention condition (baseline replacement behavior means 1.9$3.75 \%$ vs. baseline aggression means $0-1.31 \%$ ) for all three stimulus conditions.

A possible explanation for David's mixed results could be his response to naturally maintaining contingencies in the physical environment. Often during behavior modification interventions once aggressive behavior subsides, students are introduced to naturally occurring reinforcing consequences (e.g., verbal praise) that had been previously overlooked (Baer, Wolf, \& Risley, 1968; Iwata, et al., 2000). As an illustration, for David the dramatic decrease in aggression could mean that the VSM drew David's attention to natural reinforcers such as verbal praise and teacher attention, which were displayed in the video. According to behaviorism, stimuli in the physical environment following a performance (e.g., verbal praise) can cause a change in selfregulation patterns. For David, simply viewing the reinforcing consequences may have helped him appropriately regulate his behavior, rendering the replacement behavior unnecessary. Furthermore, in this study the measurement system was not designed to record responses to natural contingencies, therefore the inconsistent results in replacement behavior data for David would be plausible. It does need to be acknowledged, however, that Nate may not have been motivated by natural contingences or stimuli in the environment hence his data reflects greater instances of the replacement behavior resulting in a high intervention effect.

Another consideration could be that the replacement behavior became internalized suggesting a change in self-regulation. According to SCT self-efficacy impacts selfregulated behavior (Bandura, 1989, 1991). It's plausible to assume that the VSM offered David a chance to view himself successfully performing and receiving a desirable 
consequence, thus helping him appropriately regulate his behavior and rendering the need to request a break unnecessary. It's equally possible that Nate internalized that replacement behavior, but required the use of items that provide sensory input to regulate his behavior. Further evidence of this internalization effect is apparent during the maintenance condition when the videos ceased from being played but patterns consistent with the intervention condition continued for both participants. No matter the mechanism of change, the results are encouraging for both participants and warrant further investigation.

\section{Limitations of the Current Study and Suggestions for Future Research}

Several limitations may have affected the overall interpretations of this study and future research is needed. First, similar to other single-subject designs a small sample size was examined. Further, this study was the first of its kind; therefore, the results are in need of replication and should be interpreted with caution. Additional studies should also consider larger samples and multiple sites as a way to determine the generalizability of the results. Next, maintenance data was only collected up to one month post intervention. Whether or not the effects of the intervention were maintained beyond that date is not possible to determine. Future studies should examine the effects over a longer duration of time. Additionally, in the current study the same function (e.g., task avoidance) was targeted for both participants. The effects of a VSM and functional behavior assessment intervention should be tested on other functions for aggressive behaviors such as attention seeking behaviors, behaviors seeking accessing to materials, and sensory seeking behaviors. 
Moreover, it is unclear why the VSM has no effect on David's replacement behavior. As noted, it is possible that the decrease in aggressive behavior could indicate that David learned to appropriately regulate his behavior. Due to lingering questions, additional studies should be carried out to analyze rates of replacement and aggressive behaviors. Additional research should find ways to record responses to naturally occurring reinforcing stimuli and measure one's self-regulation skills pre/post an intervention to treat aggressive behavior.

Next, it's possible that the stimulus conditions were too similar causing some generalization effects across stimulus conditions. Finally, from the social validity data it is clear that the teachers would like to learn to how to utilize the VSM intervention to treat aggressive behavior, but they admitted that they lacked the appropriate technology skills to develop one. A future study would determine the effectiveness of teacher development and implementation of the VSM and if the same results could be achieved.

\section{Implications for Practice}

There are several potential implications for practice that emerged from this study. First, many teachers are faced with finding ways to reduce aggressive behaviors in students with ASD and ID. While some interventions are available, they do not necessarily work with all types of learners, most notably those with ASD and ID. In this study, the combination of VSM and functional behavior assessment had the ability to both reduce aggressive behaviors and increase replacement behaviors. This is beneficial to teachers because it can potentially foster a replacement behavior at a similar rate that it decreases behaviors. Moreover, there are few interventions that directly target students with ASD and ID. This intervention may prove helpful to teachers working with this 
type of student by way of reducing aggressive behaviors and increasing opportunities to learn.

Second, teachers need interventions that are not time consuming and immediate in their results. Literature supports that in virtually all VSM studies the intervention produced results that accelerated quickly from baseline performance and were maintained in follow up assessments (Bellini \& Akullian, 2007; Buggey, 2005; Dowrick 1999, 2012; Gelbar et al., 2012, Hitchcock, Dowrick, \& Prater, 2003; Schreibman et al., 2000). Of particular importance is that the VSM maintenance effects can withstand frequent interruptions common in schools (e.g., holiday breaks, schedule changes or interruptions, and/or absence from school; Bellini \& Akullian, 2007; Hitchcock, Dowrick, \& Prater, 2003). An intervention that maintains its effect ensures that teachers will not have to spend large amounts of instructional time re-teaching behaviors that have been previously addressed.

Third, this intervention draws on existing practices that are easily accessible to teachers. Functional behavior assessments are widely used to treat aggressive behaviors in classroom settings. Teachers could use the existing information (e.g., data, hypothesis of behavior function) to determine which behavior should be targeted in a VSM intervention. Finally, given that many students are using technology in the classroom the use of the VSM intervention may be a socially valid approach to use in the classroom setting. Students can utilize a VSM in their current classroom setting compared many other intervention approaches where instruction occurs one-on-one in a separate classroom.

\section{CONCLUSION}


When an individual's ability to evaluate environmental stimuli is compromised, as it is in individuals with ASD, maladaptive responses such as aggression are likely to occur (Goldin, Matson, \& Cervantes, 2014; Matson \& Adams, 2014; Patel, Day, Jones, \& Mazefsky, 2016; Pine, Guyer, Goldwin, Towbin \& Leibenlufte, 2008). Aggression is problematic for caregivers and teachers and can become debilitating for the individual. Furthermore, for individuals with ASD and ID the prognosis is poorer amongst traditional behavior intervention plans (Matson \& Shoemaker, 2009; Mazefsky et al., 2013; Rojahn, et al., 2010). Based on the results from this study, VSM and functional behavior assessment has the potential to modify both aggressive behavior and replacement behavior within a classroom setting by addressing external consequences and internal mechanisms that could account for sustained maladaptive behaviors. 
APPENDIX A

Teacher Interview Form

Teacher Interview Form [semi-structured format]

\section{BACKGROUND INFORMATION}

What is the student's preferred communication style?

Can you describe his/her level of cognitive functioning?

Has psychological testing been completed?

What types of reinforcement does he/she prefer?

What tasks or activities does he/she enjoy?

Does he/she demonstrate a preference for music, pop-culture characters, etc.?

\section{TARGET BEHAVIOR}

What does the noncompliance look like (i.e. ignore, aggression)? Ask for specific examples.

How often is the student noncompliant?

How long does the noncompliance last when it does occur?

What is the intensity/level of danger of this behavior?

What is the intensity/level of danger of this behavior?

\section{INTERVENTION STRATIGIES}

Describe the interventions that are currently being used to increase compliance, including the resources necessary to implement these interventions.

Describe previous strategies used to increase compliance, including the resources necessary to implement these interventions.

Which strategies were successful at improving compliance? What strategies were not successful at improving compliance?

What reinforcers have effectively served to increase desirable behavior in the past, 
APPENDIX B

Parent Interview Form

\section{Parent Interview Form [semi-structured format]}

PERSONAL INFORMATION

Age?

Date of birth?

Diagnosis?

(i.e.) ASD, clinical, educational, both?

Were the symptoms apparent at birth?

Discuss any early developmental milestones.

Hobbies and/or interests

(ie, musical preferences, pop-culture icons, activities)

\section{BEHAVIOR INFORMATION}

Do you notice noncompliant behavior in the home?

What does the noncompliance look like (i.e. ignore, aggression)? Ask for specific examples.

How long does the noncompliance last when it does occur?

What is the intensity/level of danger of this behavior?

\section{INTERVENTION STRATIGIES}

Describe the interventions that are currently being used to increase compliance, including the resources necessary to implement these interventions.

Describe previous strategies used to increase compliance, including the resources necessary to implement these interventions.

Which strategies were successful at improving compliance? What strategies were not successful at improving compliance?

What reinforcers have effectively served to increase desirable behavior in the past, 


\section{APPENDIX C}

Example of a Storyboard

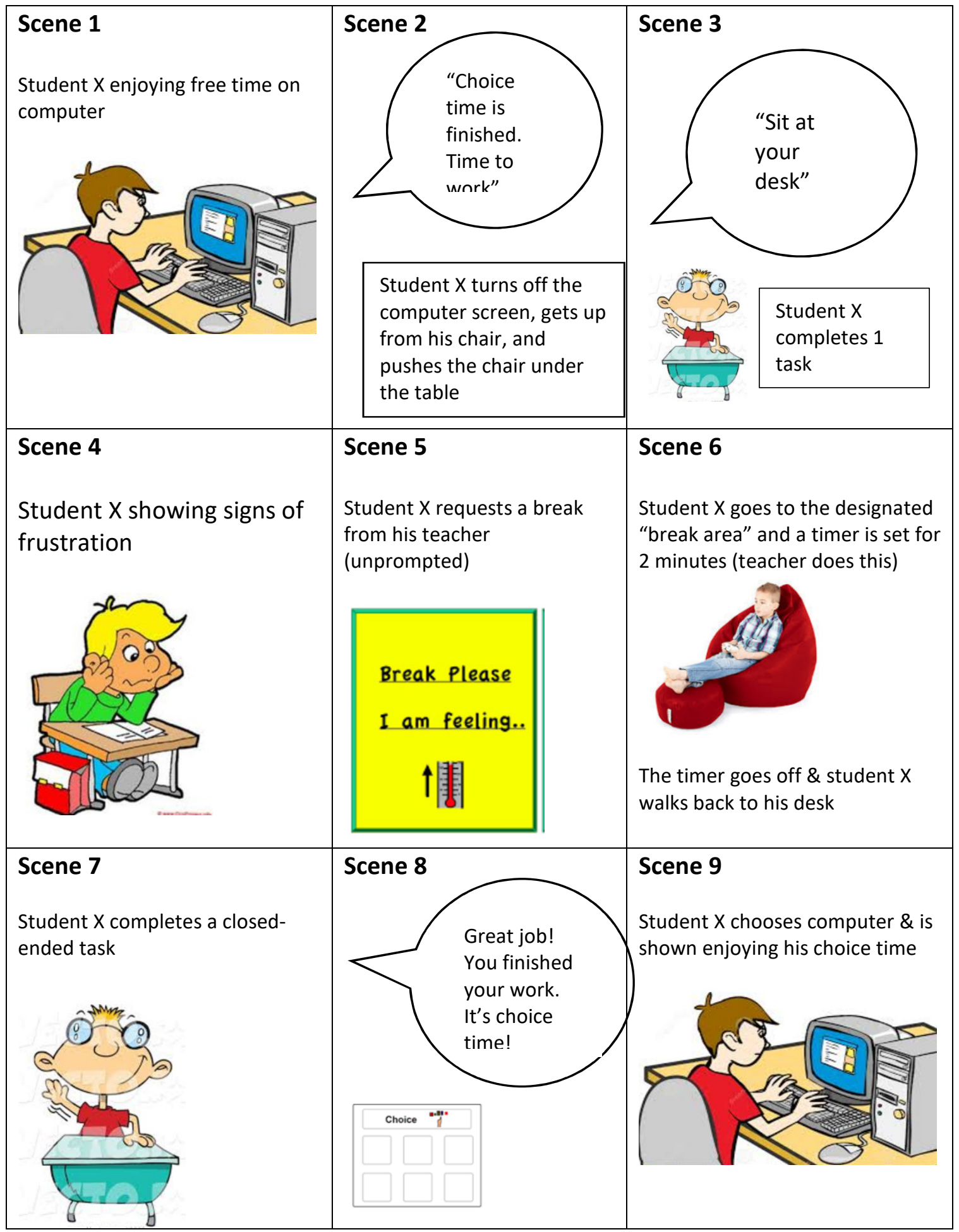




\section{APPENDIX D}

Steps for creating the VSM

Steps for creating the VSMs

(1) Determine target behavior and replacement behavior

A. Support these decisions by analyzing the results of the independent functional analysis

(2) Determine when and where the dependent variables occur

A. Create a list of situations and locations of where $\&$ when the aggressive behavior frequently occurs

B. Observe an aggressive 2-3 episodes (take notes regarding antecedent, behavior, \& consequence)

C. Observe when the replacement skill is being used (note prompt dependence and frequency of use)

D. Take pictures of any visual prompts the student is using; upload to a secure server

E. Observe the student using his/her functional communication system

F. Create a storyboard that gives an outline of what you want the VSM to portray

\section{(3) Record}

A. Using the list of situations and locations \& times that the dependent variables occur, observe the classroom from a non-intrusive position.

B. Record the antecedent, behavior, and consequence of both the aggressive behavior and the replacement skill

C. Record any approximations of the replacement skill (use physical assistance if necessary)

D. Film the student exhibiting happiness (i.e. smiling, laughing, engaging in a preferred activity)

E. If the student has a preferred teacher and/or friend film this person offering praise

F. Once an incident is recorded, upload it to a secure server and delete from the iPhone immediately

\section{(4) Edit}

A. Download videos into Movie Maker (Windows)

B. Find incidents within the video footage that replicate the scenes from the storyboard

C. Delete instances of physical aggression

D. Delete footage of teacher or para-professional assistance

E. Piece the small video clips into a cohesive sequence of appropriate behaviors

F. Using Movie Maker, add music, narration, and/or captions to the video

G. (Optional) Using Screencast-O-matic(C), add pictures and/or video clips based on the child's preferences

\section{(5) Publish}

A. Save movie in Movie Maker and publish into a format suitable for a computer and/or handheld device

B. Delete the project in Movie Maker

C. Use a flash-drive or download the video from a secure server onto the devices that the teacher has indicated for use.

D. Label the VSM with the student's initials and "_VSM" behind it 


\section{APPENDIX E}

\section{Interval Data Sheet}

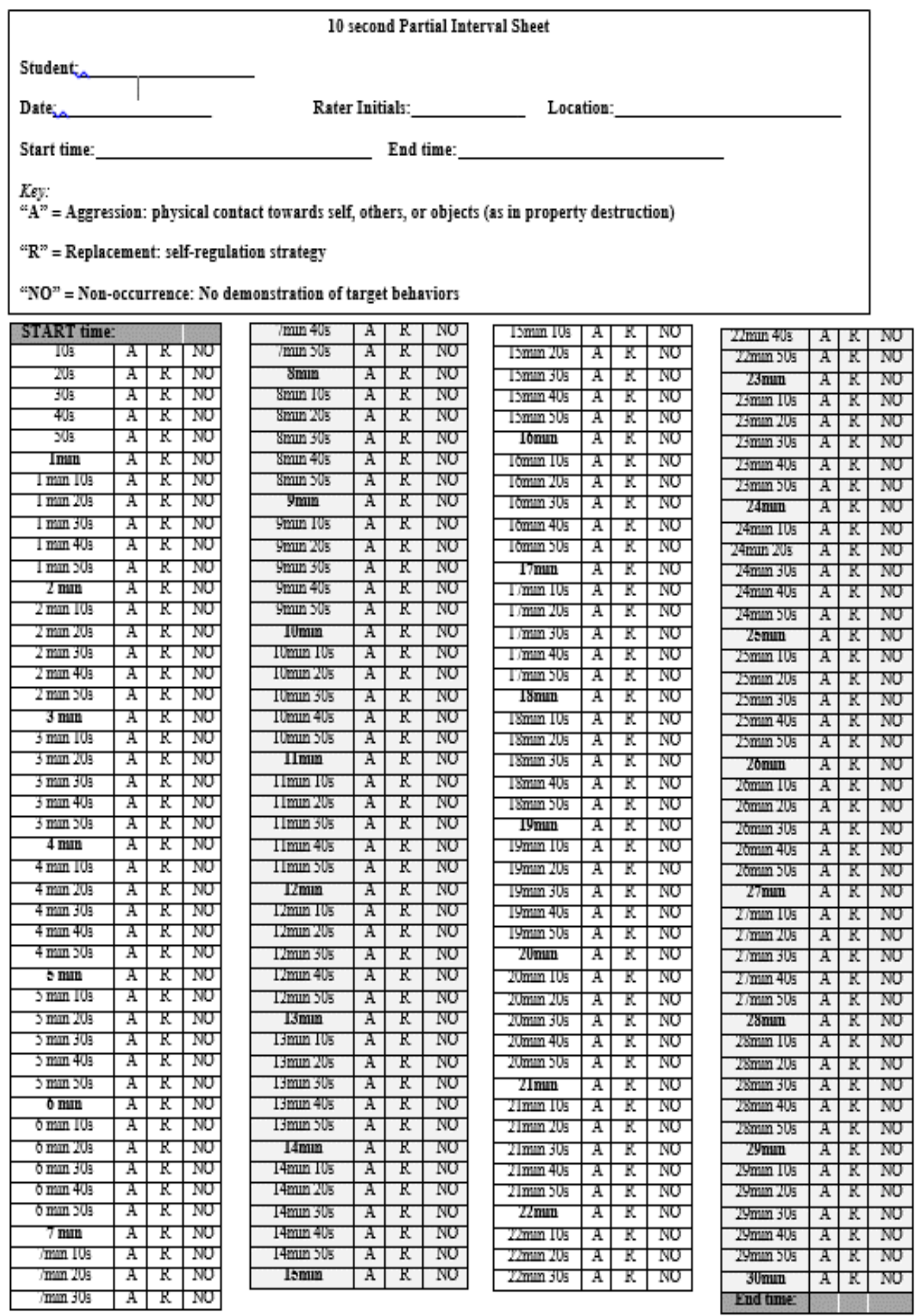




\section{APPENDIX F}

Treat Fidelity Check (David)

\section{DS DATA COLLECTION SCHEDULE}

[S1] Observe DS in classroom (30 minutes total not including reinforcement time) Possible times: 9:00-9:30, 10:00-11:00, 11:30-12:00

Fidelity check (were the behavioral expectations upheld by the staff)

\begin{tabular}{|l|l|l|l|}
\hline \multicolumn{1}{|c|}{ Expectation } & yes & no & Not applicable (why?) \\
\hline Remain seated in chair floor & & & \\
\hline Follow instructions & & & \\
\hline Self-regulation available & & & \\
\hline
\end{tabular}

[S2] Observe DS during his lunch routine

Scheduled time: 12:00-12:30

Fidelity check (were the behavioral expectations upheld by the staff)

\begin{tabular}{|l|c|c|c|}
\hline \multicolumn{1}{|c|}{ Expectation } & yes & no & Not applicable (why?) \\
\hline Lunch line (take l item) & & & \\
\hline Remain seated at table while eating & & & \\
\hline Follow instructions & & & \\
\hline Self-regulation available & & & \\
\hline
\end{tabular}

\section{[S3] Observe DS at "specials"}

Scheduled time: 12:40-1:05

Fidelity check (were the behavioral expectations upheld by the staff)

\begin{tabular}{|l|c|c|c|}
\hline \multicolumn{1}{|c|}{ Expectation } & yes & no & Not applicable (why?) \\
\hline Remain seated in chair/floor & & & \\
\hline Follow instructions & & & \\
\hline Self-regulation available & & & \\
\hline
\end{tabular}

\section{VSM FIDELITY CHECK (For INTERVENTION and MAINTAINENCE ONLY!)}

DATE:

\begin{tabular}{|l|l|l|}
\hline & $\begin{array}{l}\text { Was the video played for the student at the beginning of the } \\
\text { day? }\end{array}$ & Rater initials: \\
\hline & & \\
\hline & & \\
\hline
\end{tabular}

NOTES:

- Please record data on the attached sheets

- Turn into Kate Sadler when completed

- Keep a gafe distance away from behaviors

- If a crisis occurs follow instructions from staff members

- Try not to disrupt the environment

Thank you!!!! 


\section{APPENDIX G}

Treat Fidelity Check (Nate)

\section{NM DATA COLLECTION SCHEDULE}

\section{[S1] Observe NM for small group}

Possible times: 9:15-10:00, 2:00-2:30

Fidelity check (were the behavioral expectations upheld by the staff)

\begin{tabular}{|l|c|c|c|}
\hline \multicolumn{1}{|c|}{ Expectation } & yes & no & Not applicable (why?) \\
\hline Remain seated in chair/floor & & & \\
\hline Follow instructions & & & \\
\hline Self-regulation available & & & \\
\hline
\end{tabular}

\section{[S2] Observe NM for Center Time}

Possible times: 10:30-11:15

Fidelity check (were the behavioral expectations upheld by the staff)

\begin{tabular}{|l|c|c|c|}
\hline \multicolumn{1}{|c|}{ Expectation } & yes & no & Not applicable (why?) \\
\hline Remain seated in chair floor & & & \\
\hline Follow instructions & & & \\
\hline Self-regulation available & & & \\
\hline
\end{tabular}

[S3] Observe NM for desk work

Possible times: 1:00-2:00

Fidelity check (were the behavioral expectations upheld by the staff)

\begin{tabular}{|l|c|c|c|}
\hline \multicolumn{1}{|c|}{ Expectation } & yes & no & Not applicable (why?) \\
\hline Remain seated in chairfloor & & & \\
\hline Follow instructions & & & \\
\hline Self-regulation available & & & \\
\hline
\end{tabular}

VSM FIDELITY CHECK (For INTERVENTION and MAINTAINENCE ONLY!)

DATE:

\begin{tabular}{|l|l|l|}
\hline & $\begin{array}{l}\text { Was the video played for the student at the beginning } \\
\text { of the day? }\end{array}$ & Rater initials: \\
\hline & & \\
\hline & & \\
\hline
\end{tabular}

NOTES:

- Please record data on the attached sheets

- Turn into Kate Sadler when completed

- Keep a gafe distance away from behaviors

- If a crisis occurs follow instructions from staff members

- Try not to disrupt the environment

Thank you!!!! 


\section{REFERENCES}

American Psychiatric Association, \& American Psychiatric Association. DSM-5 Task Force. (2013). Diagnostic and statistical manual of mental disorders: DSM-5 ${ }^{\mathrm{TM}}$. Arlington, VA: American Psychiatric Publishing.

Bachevalier, J., \& Loveland, K. A. (2006). The orbitofrontal-amygdala circuit and selfregulation of social-emotional behavior in autism. Neuroscience \& Biobehavioral Reviews, 30(1), 97-117.

Baer, D. M., Wolf, M. M., \& Risley, T. R. (1968). Some current dimensions of applied behavior analysis. Journal of applied behavior analysis, 1(1), 91-97.

Bandura, A. (1965). Vicarious Processes: A Case of No-Trial Learning1. In Advances in experimental social psychology (Vol. 2, pp. 1-55). academic press.

Bandura, A. (1969). Principles of behavior modification.

Bandura, A. (1974). Behavior theory and the models of man. American psychologist, 29(12), 859.

Bandura, A. (1975). Analysis of modeling processes. School Psychology Digest.

Bandura, A. (1977). Self-efficacy: toward a unifying theory of behavioral change. Psychological review, 84(2), 191.

Bandura, A. (1978). The self system in reciprocal determinism. American psychologist, 33(4), 344.

Bandura, A. (1982). Self-efficacy mechanism in human agency. American psychologist, 37(2), 122.

Bandura, A. (1984). Recycling misconceptions of perceived self-efficacy. Cognitive therapy and research, 8(3), 231-255. 
Bandura, A. (1989). Human agency in social cognitive theory. American psychologist, 44(9), 1175.

Bandura, A. (1991). Social cognitive theory of self-regulation. Organizational behavior and human decision processes, 50(2), 248-287.

Bandura, A. (1997). Self-efficacy: The exercise of control.

Bandura, A. (2000). Exercise of human agency through collective efficacy. Current directions in psychological science, 9(3), 75-78.

Bandura, A. (2002). Social cognitive theory in cultural context. Applied psychology, 51(2), 269-290.

Bandura, A. (2012). On the functional properties of perceived self-efficacy revisited.

Baron-Cohen, S. (1988). Social and pragmatic deficits in autism: Cognitive or affective?. Journal of autism and developmental disorders, 18(3), 379-402.

Baron-Cohen, S., Leslie, A. M., \& Frith, U. (1985). Does the autistic child have a "theory of mind"?. Cognition, 21(1), 37-46.

Bauminger, N. (2002). The facilitation of social-emotional understanding and social interaction in high-functioning children with autism: Intervention outcomes. Journal of autism and developmental disorders, 32(4), 283-298.

Beck, J. S. (2011). Cognitive behavior therapy: Basics and beyond. Guilford press.

Bellini, S., \& McConnell, L. L. (2010). Strength-based educational programming for students with autism spectrum disorders: A case for video selfmodeling. Preventing School Failure: Alternative Education for Children and Youth, 54(4), 220-227.

Bellini, S., \& Akullian, J. (2007). A meta-analysis of video modeling and video self- 
modeling interventions for children and adolescents with autism spectrum disorders. Exceptional children, 73(3), 264-287.

Bellini, S., Akullian, J., \& Hopf, A. (2007). Increasing social engagement in young children with autism spectrum disorders using video self-modeling. School Psychology Review, 36(1), 80.

Boesch, M. C., Taber-Doughty, T., Wendt, O., \& Smalts, S. S. (2015). Using a behavioral approach to decrease self-injurious behavior in an adolescent with severe autism: a data-based case study. Education and Treatment of Children, 38(3), 305-328.

Boudreau, J., \& Harvey, M. T. (2013). Increasing recreational initiations for children who have ASD using video self modeling. Education and Treatment of Children, 36(1), 49-60.

Braithwaite, K. L., \& Richdale, A. L. (2000). Functional communication training to replace challenging behaviors across two behavioral outcomes. Behavioral Interventions, 15(1), 21-36.

Bronsard, G., Botbol, M., \& Tordjman, S. (2010). Aggression in low functioning children and adolescents with autistic disorder. PLoS One, 5(12), e14358.

Browder, D. M., Wood, L., Thompson, J., \& Ribuffo, C. (2014). Evidence-based practices for students with severe disabilities. University of Florida.

Buggey, T. (2005). Video self-modeling applications with students with autism spectrum disorder in a small private school setting. Focus on autism and other developmental disabilities, 20(1), 52-63.

Buggey, T. (2009). Seeing is believing: Video self-modeling for people with autism and other developmental disabilities. 
Buggey, T. (2012). Effectiveness of video self-modeling to promote social initiations by 3-year-olds with autism spectrum disorders. Focus on Autism and Other Developmental Disabilities, 27(2), 102-110.

Buggey, T., Hoomes, G., Sherberger, M. E., \& Williams, S. (2011). Facilitating social initiations of preschoolers with autism spectrum disorders using video selfmodeling. Focus on Autism and Other Developmental Disabilities, 26(1), 25-36.

Buggey, T., Toombs, K., Gardener, P., \& Cervetti, M. (1999). Training responding behaviors in students with autism: Using videotaped self-modeling. Journal of Positive Behavior Interventions, 1(4), 205-214.

Burton, C. E., Anderson, D. H., Prater, M. A., \& Dyches, T. T. (2013). Video selfmodeling on an iPad to teach functional math skills to adolescents with autism and intellectual disability. Focus on Autism and Other Developmental Disabilities, 28(2), 67-77.

Carlson, S. M., \& Moses, L. J. (2001). Individual differences in inhibitory control and children's theory of mind. Child development, 72(4), 1032-1053.

Carr, E. G., Newsom, C. D., \& Binkoff, J. A. (1980). Escape as a factor in the aggressive behavior of two retarded children. Journal of Applied Behavior Analysis, 13(1), $101-117$.

Carr, E. G., \& Durand, V. M. (1985). Reducing behavior problems through functional communication training. Journal of applied behavior analysis, 18(2), 111-126.

Carroll, C., Patterson, M., Wood, S., Booth, A., Rick, J., \& Balain, S. (2007). A conceptual framework for implementation fidelity. Implementation science, 2(1), 40. 
Carroll, D., Hallett, V., McDougle, C. J., Aman, M. G., McCracken, J. T., Tierney, E., \& Swiezy, N. (2014). Examination of aggression and self-injury in children with autism spectrum disorders and serious behavioral problems. Child and adolescent psychiatric clinics of North America, 23(1), 57-72.

Chalfant, A. M., Rapee, R., \& Carroll, L. (2007). Treating anxiety disorders in children with high functioning autism spectrum disorders: A controlled trial. Journal of autism and developmental disorders, 37(10), 1842-1857.

Charlop-Christy, M. H., \& Haymes, L. K. (1996). Using obsessions as reinforcers with and without mild reductive procedures to decrease inappropriate behaviors of children with autism. Journal of autism and developmental disorders, 26(5), 527546.

Cihak, D. F., \& Schrader, L. (2008). Does the model matter? Comparing video selfmodeling and video adult modeling for task acquisition and maintenance by adolescents with autism spectrum disorders. Journal of Special Education Technology, 23(3), 9-20.

Cihak, D., Fahrenkrog, C., Ayres, K. M., \& Smith, C. (2010). The use of video modeling via a video iPod and a system of least prompts to improve transitional behaviors for students with autism spectrum disorders in the general education classroom. Journal of Positive Behavior Interventions, 12(2), 103-115.

Clearinghouse, W. W. (2008). WWC procedures and standards handbook. Washington, DC: Retrieved January, 1, 2009.

Corbett, B. A., \& Abdullah, M. (2005). Video modeling: Why does it work for children with autism?. Journal of Early and Intensive Behavior Intervention, 2(1), 2. 
Coyle, C., \& Cole, P. (2004). A videotaped self-modelling and self-monitoring treatment program to decrease off-task behaviour in children with autism. Journal of Intellectual and Developmental disability, 29(1), 3-16.

Creer, T. L., \& Miklich, D. R. (1970). The application of a self-modeling procedure to modify inappropriate behavior: A preliminary report. Behaviour Research and Therapy, 8(1), 91-92.

Davis, T. N., Dacus, S., Strickland, E., Copeland, D., Chan, J. M., Blenden, K., \& C Christian, K. (2013). The effects of a weighted vest on aggressive and selfinjurious behavior in a child with autism. Developmental neurorehabilitation, 16(3), 210-215.

Dooley, P., Wilczenski, F. L., \& Torem, C. (2001). Using an activity schedule to smooth school transitions. Journal of Positive Behavior Interventions, 3(1), 57-61.

Dowrick, P. W. (1999). A review of self modeling and related interventions. Applied and preventive psychology, 8(1), 23-39.

Dowrick, P. W. (2012). Self modeling: Expanding the theories of learning. Psychology in the Schools, 49(1), 30-41.

Durand, V. M. (1999). Functional communication training using assistive devices: Recruiting natural communities of reinforcement. Journal of Applied Behavior Analysis, 32(3), 247-267.

Falcomata, T. S., Roane, H. S., Muething, C. S., Stephenson, K. M., \& Ing, A. D. (2012). Functional communication training and chained schedules of reinforcement to treat challenging behavior maintained by terminations of activity interruptions. Behavior Modification, 36(5), 630-649. 
Farmer, C. A., \& Aman, M. G. (2011). Aggressive behavior in a sample of children with autism spectrum disorders. Research in Autism Spectrum Disorders, 5(1), 317323.

Farmer, C., Butter, E., Mazurek, M. O., Cowan, C., Lainhart, J., Cook, E. H., ... \& Aman, M. (2015). Aggression in children with autism spectrum disorders and a clinicreferred comparison group. Autism, 19(3), 281-291.

Fisher, W. W., Groff, R. A., \& Roane, H. S. (2011). Applied behavior analysis: History, philosophy, principles, and basic methods. Handbook of applied behavior analysis, 3-13.

Foxx, R. M., \& Garito, J. (2007). The long term successful treatment of the very severe behaviors of a preadolescent with autism. Behavioral Interventions, 22(1), 69-82.

Foxx, R. M., \& Meindl, J. (2007). The long term successful treatment of the aggressive/destructive behaviors of a preadolescent with autism. Behavioral Interventions, 22(1), 83-97.

Frea, W. D., Arnold, C. L., \& Vittimberga, G. L. (2001). A demonstration of the effects of augmentative communication on the extreme aggressive behavior of a child with autism within an integrated preschool setting. Journal of positive behavior interventions, 3(4), 194-198.

Gelbar, N. W., Anderson, C., McCarthy, S., \& Buggey, T. (2012). Video self-modeling as an intervention strategy for individuals with autism spectrum disorders. Psychology in the Schools, 49(1), 15-22.

Goldin, R. L., Matson, J. L., \& Cervantes, P. E. (2014). The effect of intellectual 
disability on the presence of comorbid symptoms in children and adolescents with autism spectrum disorder. Research in Autism Spectrum Disorders, 8(11), 15521556.

Gotham, K., Brunwasser, S. M., \& Lord, C. (2015). Depressive and anxiety symptom trajectories from school age through young adulthood in samples with autism spectrum disorder and developmental delay. Journal of the American Academy of Child \& Adolescent Psychiatry, 54(5), 369-376.

Hanley, G. P., Iwata, B. A., \& McCord, B. E. (2003). Functional analysis of problem behavior: A review. Journal of applied behavior analysis, 36(2), 147-185.

Hariri, A. R., Bookheimer, S. Y., \& Mazziotta, J. C. (2000). Modulating emotional responses: effects of a neocortical network on the limbic system. Neuroreport, 11(1), 43-48.

Hart, J. E., \& Whalon, K. J. (2012). Using video self-modeling via iPads to increase academic responding of an adolescent with autism spectrum disorder and intellectual disability. Education and Training in Autism and Developmental Disabilities, 438-446.

Heckaman, K. A., Alber, S., Hooper, S., \& Heward, W. L. (1998). A comparison of leastto-most prompts and progressive time delay on the disruptive behavior of students with autism. Journal of Behavioral Education, 8(2), 171-201.

Hitchcock, C. H., Dowrick, P. W., \& Prater, M. A. (2003). Video self-modeling intervention in school-based settings: A review. Remedial and Special Education, 24(1), 36-45.

Horner, R. H., Carr, E. G., Halle, J., McGee, G., Odom, S., \& Wolery, M. (2005). The 
use of single-subject research to identify evidence-based practice in special education. Exceptional children, 71(2), 165-179.

Horner, R. H., Carr, E. G., Strain, P. S., Todd, A. W., \& Reed, H. K. (2002). Problem behavior interventions for young children with autism: A research synthesis. Journal of autism and developmental disorders, 32(5), 423-446.

Hosford, R. E. (1981). Self-as-a-model: A cognitive social learning technique. The counseling psychologist, 9(1), 45-62.

Hume, K., Loftin, R., \& Lantz, J. (2009). Increasing independence in autism spectrum disorders: A review of three focused interventions. Journal of autism and developmental disorders, 39(9), 1329-1338.

Iwata, B. A., Kahng, S. W., Wallace, M. D., \& Lindberg, J. S. (2000). The functional analysis model of behavioral assessment.

Jang, J., Dixon, D. R., Tarbox, J., \& Granpeesheh, D. (2011). Symptom severity and challenging behavior in children with ASD. Research in Autism Spectrum Disorders, 5(3), 1028-1032.

Jessel, J., Hanley, G. P., \& Ghaemmaghami, M. (2016). Interview-informed synthesized contingency analyses: Thirty replications and reanalysis. Journal of applied behavior analysis, 49(3), 576-595.

Kamphaus, R. W. (1992). Behavior Assessment System for Children, (BASC-2). The Encyclopedia of Clinical Psychology.

Kanne, S. M., \& Mazurek, M. O. (2011). Aggression in children and adolescents with ASD: Prevalence and risk factors. Journal of autism and developmental disorders, 41(7), 926-937. 
Kern, L., Carberry, N., \& Haidara, C. (1997). Analysis and intervention with two topographies of challenging behavior exhibited by a young woman with autism. Research in Developmental Disabilities, 18(4), 275-287.

Kratochwill, T. R., \& Levin, J. R. (2014). Single-case intervention research: Methodological and statistical advances. American Psychological Association.

Lovaas, O. I., Koegel, R. L., \& Schreibman, L. (1979). Stimulus overselectivity in autism: a review of research. Psychological bulletin, 86(6), 1236.;

Ma, H. H. (2006). An alternative method for quantitative synthesis of single-subject researches: Percentage of data points exceeding the median. Behavior modification, 30(5), 598-617.

Marcus, A., \& Wilder, D. A. (2009). A comparison of peer video modeling and self video modeling to teach textual responses in children with autism. Journal of applied behavior analysis, 42(2), 335-341.

Mason, R. A., Davis, H. S., Ayres, K. M., Davis, J. L., \& Mason, B. A. (2016). Video self-modeling for individuals with disabilities: A best-evidence, single case metaanalysis. Journal of Developmental and Physical Disabilities, 28(4), 623-642.

Matson, J. L., \& Adams, H. L. (2014). Characteristics of aggression among persons with autism spectrum disorders. Research in Autism Spectrum Disorders, 8(11), 15781584.

Matson, J. L., \& Jang, J. (2014). Treating aggression in persons with autism spectrum disorders: a review. Research in developmental disabilities, 35(12), 3386-3391.

Matson, J. L., \& Shoemaker, M. (2009). Intellectual disability and its relationship to 
autism spectrum disorders. Research in developmental disabilities, 30(6), 11071114

Matson, J. L., \& Vollmer, T. R. (1995). User's guide: Questions about behavioral function (QABF). Baton Rouge, LA: Scientific Publishers.

Mazefsky, C. A., Herrington, J., Siegel, M., Scarpa, A., Maddox, B. B., Scahill, L., \& White, S. W. (2013). The role of emotion regulation in autism spectrum disorder. Journal of the American Academy of Child \& Adolescent Psychiatry, 52(7), 679-688.

Mazefsky, C. A., \& White, S. W. (2014). Emotion regulation: Concepts \& practice in autism spectrum disorder. Child and adolescent psychiatric clinics of North America, 23(1), 15-24.

Mazurek, M. O., Kanne, S. M., \& Wodka, E. L. (2013). Physical aggression in children and adolescents with autism spectrum disorders. Research in Autism Spectrum Disorders, 7(3), 455-465.

McTiernan, A., Leader, G., Healy, O., \& Mannion, A. (2011). Analysis of risk factors and early predictors of challenging behavior for children with autism spectrum disorder. Research in Autism Spectrum Disorders, 5(3), 1215-1222.

Medeiros, K., Kozlowski, A. M., Beighley, J. S., Rojahn, J., \& Matson, J. L. (2012). The effects of developmental quotient and diagnostic criteria on challenging behaviors in toddlers with developmental disabilities. Research in developmental disabilities, 33(4), 1110-1116.

Mueller, M. M., Wilczynski, S. M., Moore, J. W., Fusilier, I., \& Trahant, D. (2001). 
Antecedent manipulations in a tangible condition: Effects of stimulus preference on aggression. Journal of Applied Behavior Analysis, 34(2), 237-240.

Murphy, O., Healy, O., \& Leader, G. (2009). Risk factors for challenging behaviors among 157 children with autism spectrum disorder in Ireland. Research in Autism Spectrum Disorders, 3(2), 474-482.

Neely, L., Rispoli, M., Camargo, S., Davis, H., \& Boles, M. (2013). The effect of instructional use of an iPad® on challenging behavior and academic engagement for two students with autism. Research in Autism Spectrum Disorders, 7(4), 509516.

O’Reilly, M., Sigafoos, J., Lancioni, G., Edrisinha, C., \& Andrews, A. (2005). An examination of the effects of a classroom activity schedule on levels of self-injury and engagement for a child with severe autism. Journal of Autism and Developmental Disorders, 35(3), 305-311.

Odom, S. L., \& Strain, P. S. (2002). Evidence-based practice in early intervention/early childhood special education: Single-subject design research. Journal of Early Intervention, 25(2), 151-160.

Patel, S., Day, T. N., Jones, N., \& Mazefsky, C. A. (2017). Association between anger rumination and autism symptom severity, depression symptoms, aggression, and general dysregulation in adolescents with autism spectrum disorder. Autism, 21(2), 181-189.

Pine, D. S., Guyer, A. E., Goldwin, M., Towbin, K. A., \& Leibenluft, E. (2008). Autism spectrum disorder scale scores in pediatric mood and anxiety disorders. Journal of the American Academy of Child \& Adolescent Psychiatry, 47(6), 652-661. 
Pouw, L. B., Rieffe, C., Oosterveld, P., Huskens, B., \& Stockmann, L. (2013).

Reactive/proactive aggression and affective/cognitive empathy in children with ASD. Research in developmental disabilities, 34(4), 1256-1266.

Rayner, C., Denholm, C., \& Sigafoos, J. (2009). Video-based intervention for individuals with autism: Key questions that remain unanswered. Research in Autism Spectrum Disorders, 3(2), 291-303.

Reaven, J., Blakeley-Smith, A., Culhane-Shelburne, K., \& Hepburn, S. (2012). Group cognitive behavior therapy for children with high-functioning autism spectrum disorders and anxiety: A randomized trial. Journal of Child Psychology and Psychiatry, 53(4), 410-419.

Reese, R. M., Richman, D. M., Belmont, J. M., \& Morse, P. (2005). Functional characteristics of disruptive behavior in developmentally disabled children with and without autism. Journal of Autism and Developmental Disorders, 35(4), 419428.

Rojahn, J., Wilkins, J., Matson, J. L., \& Boisjoli, J. (2010). A comparison of adults with intellectual disabilities with and without ASD on parallel measures of challenging behaviour: The Behavior Problems Inventory-01 (BPI-01) and Autism Spectrum Disorders-Behavior Problems for Intellectually Disabled Adults (ASDBPA). Journal of Applied Research in Intellectual Disabilities, 23(2), 179-185.

Rosenwasser, B., \& Axelrod, S. (2001). The contributions of applied behavior analysis to the education of people with autism. Behavior modification, 25(5), 671-677.

Rutter, M., Le Couteur, A., \& Lord, C. (2003). Autism diagnostic interview-revised. Los Angeles, CA: Western Psychological Services, 29, 30. 
Schatz, R. B., Peterson, R. K., \& Bellini, S. (2016). The use of video self-modeling to increase on-task behavior in children with high-functioning autism. Journal of Applied School Psychology, 32(3), 234-253.

Scheuermann, B. K., \& Hall, J. A. (2011). Positive behavioral supports for the classroom. Pearson Higher Ed.

Schindler, H. R., \& Horner, R. H. (2005). Generalized reduction of problem behavior of young children with autism: Building trans-situational interventions. American Journal on Mental Retardation, 110(1), 36-47.

Schreibman, L., Whalen, C., \& Stahmer, A. C. (2000). The use of video priming to reduce disruptive transition behavior in children with autism. Journal of positive behavior interventions, 2(1), 3-11.

Schmitz, N., Rubia, K., Daly, E., Smith, A., Williams, S., \& Murphy, D. G. (2006). Neural correlates of executive function in autistic spectrum disorders. Biological psychiatry, 59(1), 7-16.

Schunk, D. H. (2012). Learning theories an educational perspective sixth edition. Pearson.

Sherer, M., Pierce, K. L., Paredes, S., Kisacky, K. L., Ingersoll, B., \& Schreibman, L. (2001). Enhancing conversation skills in children with autism via video technology: Which is better, "self" or "other" as a model?. Behavior modification, 25(1), 140-158.

Siegel, M. (2012). Psychopharmacology of autism spectrum disorder: evidence and practice. Child and adolescent psychiatric clinics of North America, 21(4), 957973. 
Skinner, B. F. (1953). Science and human behavior. Simon and Schuster.

Skinner, B. F. (1973). Self-control. Behavior change through self-control. New York: Holt, Rinehart \& Winston.

Storch, E. A., Ehrenreich May, J., Wood, J. J., Jones, A. M., De Nadai, A. S., Lewin, A. B., \& Murphy, T. K. (2012). Multiple informant agreement on the anxiety disorders interview schedule in youth with autism spectrum disorders. Journal of Child and Adolescent Psychopharmacology, 22(4), 292-299.

Sung, M., Ooi, Y. P., Goh, T. J., Pathy, P., Fung, D. S., Ang, R. P., ... \& Lam, C. M. (2011). Effects of cognitive-behavioral therapy on anxiety in children with autism spectrum disorders: A randomized controlled trial. Child Psychiatry \& Human Development, 42(6), 634-649.

Vannest, K. J., \& Ninci, J. (2015). Evaluating intervention effects in single-case research designs. Journal of Counseling \& Development, 93(4), 403-411.

Wang, P., \& Spillane, A. (2009). Evidence-based social skills interventions for children with autism: A meta-analysis. Education and Training in Developmental Disabilities, 318-342.

Watson, J. B. (1928). The ways of behaviorism. New York and London: Harper \& Brothers, 1928.

Wert, B. Y., \& Neisworth, J. T. (2003). Effects of video self-modeling on spontaneous requesting in children with autism. Journal of positive behavior interventions, 5(1), 30-34.

Westen, D., Blagov, P. S., Harenski, K., Kilts, C., \& Hamann, S. (2006). Neural bases of 
motivated reasoning: An fMRI study of emotional constraints on partisan political judgment in the 2004 US presidential election. Journal of cognitive neuroscience, 18(11), 1947-1958.

Westing, D. L. (2015). Evidence-based practices for improving challenging behaviors of students with severe disabilities (Document No. IC-14). Retrieved from University of Florida, Collaboration for Effective Educator, Development, Accountability, and Reform Center website:

$\underline{\text { http://ceedar.education.ufl.edu/tools/innovation-configurations/ }}$

White, S. W., Albano, A. M., Johnson, C. R., Kasari, C., Ollendick, T., Klin, A., ... \& Scahill, L. (2010). Development of a cognitive-behavioral intervention program to treat anxiety and social deficits in teens with high-functioning autism. Clinical Child And Family Psychology Review, 13(1), 77-9 
VITA

Born and raised in Saint Louis, Missouri, Kate Sadler knew at an early age that she would to devote her life to working with children with disabilities. During high school she volunteered, and later was a teacher at United Services for Children, an organization that provides early intervention services and pediatric therapy to children with developmental disabilities or delays. Those initial experiences helped to form Kate's belief that students with challenges could exceed expectations if their individual needs and abilities were identified and supported. After obtaining her bachelor's degree in Special Education at Southeast Missouri State University in 2001, she focused her efforts on instructing children significantly impacted by disabilities for over fifteen years in various classroom settings. At the University of Missouri, she obtained both her Masters of Education and Doctorate of Philosophy in Special Education. Kate's current research involves the development and testing of interventions and assessments for students with Autism Spectrum Disorder and Intellectual Disabilities. Her work has been recognized by grant funding, awards and fellowships.

Kate Sadler lives in Kirkwood, Missouri with her husband Greg, and their eightyear-old daughter, Ellinore. They are a constant source of support, pride and comfort to Kate as she continues to be inspired and challenged by the students, families, and teachers that she encounters. 